\title{
Article \\ Relative Stability of Boron Planar Clusters in Diatomic Molecular Model
}

\author{
Levan Chkhartishvili ${ }^{1,2}$
}

check for updates

Citation: Chkhartishvili, L. Relative Stability of Boron Planar Clusters in Diatomic Molecular Model. Molecules 2022, 27, 1469. https://doi.org/ $10.3390 /$ molecules 27051469

Academic Editors: Takahiro Kondo, Iwao Matsuda and Josep

M. Oliva-Enrich

Received: 27 December 2021

Accepted: 12 February 2022

Published: 22 February 2022

Publisher's Note: MDPI stays neutral with regard to jurisdictional claims in published maps and institutional affiliations.

Copyright: (c) 2022 by the author. Licensee MDPI, Basel, Switzerland. This article is an open access article distributed under the terms and conditions of the Creative Commons Attribution (CC BY) license (https:// creativecommons.org/licenses/by/ $4.0 /)$.
1 Department of Engineering Physics, Georgian Technical University, 77 Merab Kostava Avenue, Tbilisi 0160, Georgia; levanchkhartishvili@gtu.ge

2 Boron and Powder Composite Materials Laboratory, Ferdinand Tavadze Metallurgy and Materials Science Institute, 8b Elizbar Mindeli Street, Tbilisi 0186, Georgia

\begin{abstract}
In the recently introduced phenomenological diatomic molecular model imagining the clusters as certain constructions of pair interatomic chemical bonds, there are estimated specific (per atom) binding energies of small all-boron planar clusters $\mathrm{B}_{n}, n=1-15$, in neutral single-anionic and single-cationic charge states. The theoretically obtained hierarchy of their relative stability/formation probability correlates not only with results of previous calculations, but also with available experimental mass-spectra of boron planar clusters generated in process of evaporation/ablation of boron-rich materials. Some overestimation in binding energies that are characteristic of the diatomic approach could be related to differences in approximations made during previous calculations, as well as measurement errors of these energies. According to the diatomic molecular model, equilibrium binding energies per $\mathrm{B}$ atom and $\mathrm{B}-\mathrm{B}$ bond lengths are expected within ranges $0.37-6.26 \mathrm{eV}$ and $1.58-1.65 \AA$, respectively.
\end{abstract}

Keywords: planar cluster; charge state; bond length; specific binding energy; relative stability; formation probability; boron

\section{Introduction}

Nanoboron and boron-rich nanomaterials are of current academic and practical interests because of their widely variable interatomic bonding mechanism and related unique complex of physical-chemical properties useful in technological applications-see some of the reviews in the last decade [1-9].

Among them, the all-boron clusters $\mathrm{B}_{n}, n=2,3,4, \ldots$, as individual species in the gas phase, play an important role, as they can serve for building blocks in the boron-rich solids chemistry [10]. For example, a quasi-planar boron cluster $\mathrm{B}_{35}$ with a double-hexagonal hole at the center has been reported [11] as a flexible structural motif for borophene allotropies, as it can be used to construct atom-thin boron sheets with various hexagonal hole densities.

In this regard, it should be noted that, depending on the number of atoms and also formation kinetics, boron clusters can take several different shapes. Joint experimental studies and computational simulations revealed [12] that boron clusters, which favor (quasi)planar, i.e., 2D, structures up to 18 atoms, prefer 3D structures beginning at 20 atoms. The $\mathrm{B}_{20}$ neutral cluster was found to have a double-ring tubular ground structure. As for the $\mathrm{B}_{20}{ }^{-}$anion, its tubular structure was shown to be almost isoenergetic to 2D structures. Thus, the usually observed 2D-to-3D structural transition suggests that $\mathrm{B}_{20}$ may be considered as the embryo of thinnest single-walled boron nanotubes. According to the QC (Quantum Chemical) and DFT (Density Functional Theory) investigations [13], there are two structural transitions that are expected in boron clusters: the second transition from double-ring system into triple-ring one occurs between $\mathrm{B}_{52}$ and $\mathrm{B}_{54}$.

At low (namely, from 7 to 20) nuclearities, i.e., for (quasi)planar boron clusters, the separate quantum rules of in- and out-of-plane bonding were obtained [14], using the freeparticle-on-disk and rectangle models combined with DFT electronic structure calculations. 
In this Introduction, the quite-rich data available on boron clusters synthesis methods, binding parameters and their potential applications are only briefly discussed.

\subsection{Synthesizing}

Boron quasi-planar clusters can be formed in process of thermal vaporization [15-21], bombardment with high-energy particles [22], even grinding of boron-rich solid materials [23-25] and mainly by their laser ablation [26-29].

An effective method of thermal generating of pure boron cluster-ions for their further use as a plasma-process feed gas was proposed by Becker [18]. Chamber's electrode material is a compound of boron with Me metal(s) thermally decomposable within a suitable temperature range to provide boron in the vapor, but other species are substantially not in the vapor states. Magnetic confinement of the simultaneously released electrons causes numerous collisions, resulting in boron vapor ionization to the plasma state. This plasma is then extracted and accelerated at a suitable energy toward the workpiece. Created in this way, boron clusters can be self-assembled into nanostructures [19].

As early as in References [23,24], electron microscopic study of the elementary boron powder structure revealed that ultrafine particles (of $\leq 200 \AA ̊$ size) of freely grown boron are characterized by a stable 2D shape with almost hexagonal profile and aspect ratio of $\sim 20: 1$. Computer simulations were performed [25] to model structural relaxation in 2D-clusters mimicking these boron small particles.

Theoretically, using DFT, a growth path for small boron clusters $\mathrm{B}_{n}$ was discussed [30] with a size range and isomers structure. The thermochemical parameters that were determined by using coupled-cluster theory calculations suggested [31] the evolution of geometry and resonance energy of $\mathrm{B}_{n}$ clusters through the number of $\mathrm{B}-\mathrm{B}$ bonds. Based on the known geometrical characteristics of boron clusters, their general growth mechanism was proposed in Reference [32]. Moreover, a systematic structural investigation of $\mathrm{B}_{n}$ clusters established a picture of their growth behavior [33].

\subsection{Structure and Binding}

According to References $[15,34]$, the diboron molecule $\mathrm{B}_{2}$ experimental dissociation energy is within range of $2.82 \pm 0.24$ or $2.69 \pm 0.43 \mathrm{eV}$, respectively. The absorption transition at 3200-3300 $\AA$ observed in $\mathrm{B}_{2}$ indicated [35] that its ground electronic state should be the lower state of $\Sigma$-type. Moreover, as $B_{2}$ was not observed via ESR (Electron Spin Resonance), the ground electronic state was identified with ${ }^{3} \Sigma_{\mathrm{g}}{ }^{-}$. An accurate CI (Configuration Interaction) calculation confirmed [36] that mentioned transition is from the first excited state of ${ }^{3} \Sigma_{\mathrm{u}}{ }^{-}$type. Molecular binding energy for $\mathrm{B}_{2}$ at the HF (HartreeFock) level of theory [37] is $2.861 \mathrm{eV}$, and its scaled ground-state harmonic frequency equals to $0.120 \mathrm{eV}$. From the DFT calculations [30], these parameters are 2.718 and $0.134 \mathrm{eV}$, respectively. By using the $\mathrm{MO}$ (Molecular Orbitals) method, the dissociation energy of $\mathrm{B}_{2}$ ground state was calculated to be $2.71 \mathrm{eV}$ [38]. Handbook [39] recommends the diboron molecule ground electron state dissociation energy of $3.02 \mathrm{eV}$. In this state, its bond length and vibration quantum are $1.590 \AA$ and $0.130 \mathrm{eV}$, and in the first excited state, they are $1.625 \AA$ and $0.116 \mathrm{eV}$, respectively. The term of corresponding transition equals to $3.79 \mathrm{eV}$.

Potential energy curves for the states of $\mathrm{B}_{2}$ were constructed by the complete-activespace SCF (Self Consistent Field) method at the multi-reference CI level [36]. According to other multi-reference CI study [40], its ground-state curve parameters-bond length, dissociation energy and relative vibration quantum are of 1.600-1.607 $\AA, 2.70-2.78$ and $0.128-0.129 \mathrm{eV}$, respectively. For the $\mathrm{B}_{2}$ molecule ground-state interatomic potential energy, $P$ curve $P-d$, where $d$ is the inter-nuclear distance, constructed [41,42] within quasiclassical approach (Figure 1), the curve's parameters are as follows: dissociation energy of $2.80 \mathrm{eV}$, equilibrium bond length of $1.78 \AA$ and vibration quantum of $0.13 \mathrm{eV}$. Based on explicit expressions for intersite distances in boron nanotubes of regular geometry in terms of $\mathrm{B}-\mathrm{B}$ bonds length and using this quasi-classical B-B pair potential, there were estimated some ground-state parameters of boron nanotubes [43-45]. 


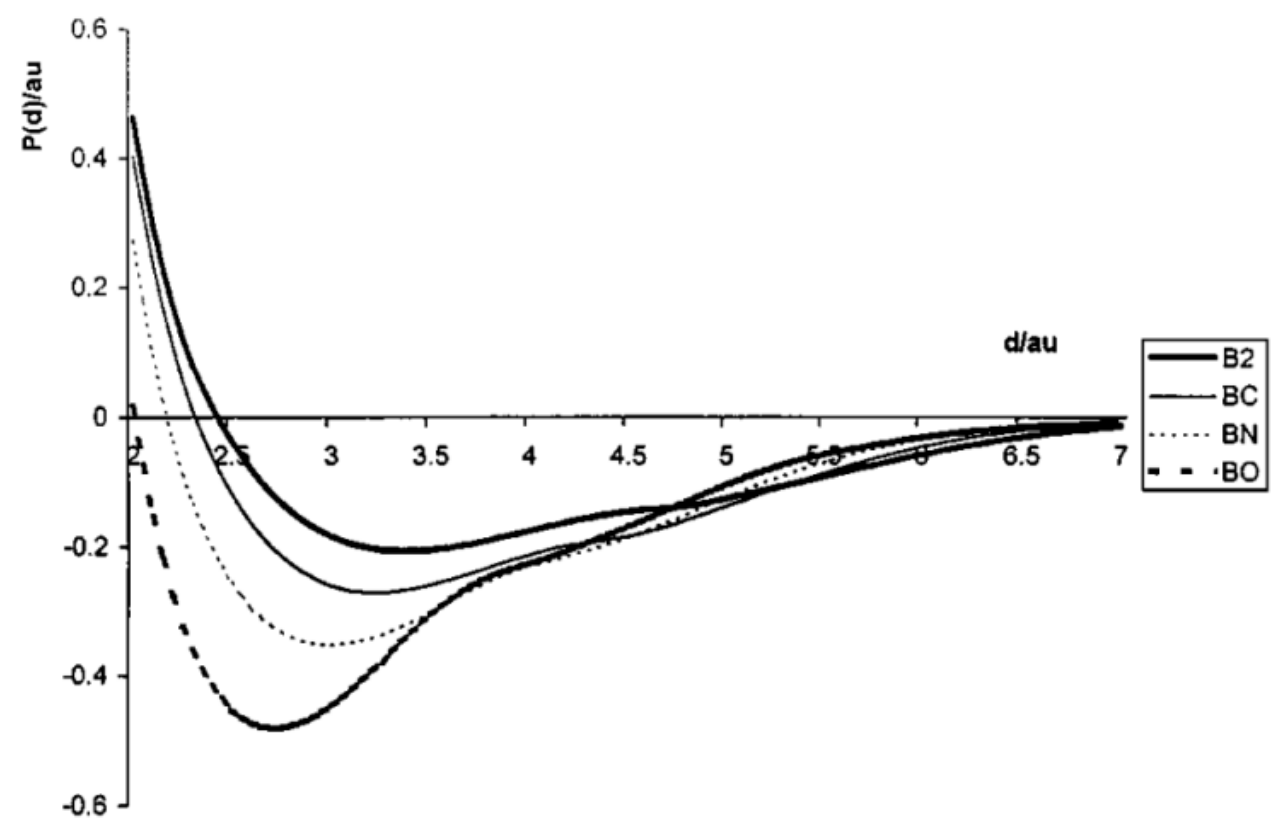

Figure 1. Quasi-classically calculated interatomic potentials for boron-containing diatomic molecules $\mathrm{B}_{2}$, $\mathrm{BC}, \mathrm{BN}$ and BO versus inter-nuclear distances [42]. Copyright (2000), with permission from Elsevier.

The potential curves, transition energies, bond lengths and vibration frequencies of ground and some of low-lying excited electronic states of $\mathrm{B}_{2}{ }^{+}$and $\mathrm{B}_{2}$ were obtained by using a CI approach [46]. The $\mathrm{B}_{2}{ }^{+}$cation ground state, which was found to $\mathrm{be}^{2} \Sigma_{\mathrm{g}}{ }^{+}$, shows a rather shallow potential curve with a bond length of $2.125 \AA$ and vibration quantum of $0.052 \mathrm{eV}$, when compared with that of the ${ }^{3} \Sigma_{\mathrm{g}}{ }^{-}$state of $\mathrm{B}_{2}$ neutral: $1.592 \AA$ and $0.131 \mathrm{eV}$. The first excited state of $\mathrm{B}_{2}{ }^{+},{ }^{2} \Pi_{\mathrm{u}}$, lies at $0.30 \mathrm{eV}$. As a result of loss of bonding electron, the ground-state dissociation energy for $\mathrm{B}_{2}{ }^{+}$with calculated value of $1.94 \mathrm{eV}$ is smaller than that of $B_{2}$.

In Reference [47], the local nature of different types of boron-boron bonds from the topological analysis of ELF (Electron Localization Function) perspective was investigated in 23 boron-containing molecules.

Initially, Boustani demonstrated that stable structures of neutral bare boron clusters, $\mathrm{B}_{n}$, with $n=12,16,22,32,42$ and 46 , can easily be constructed with the help of the so-called Aufbau Principle suggested on the basis of HF SCF direct CI [48], as well as QC, DFT and LMTO (Linear Muffin Tin Orbital) [49,50] studies.

Based on different theoretical approaches, such as LDA (Local Density Approximation) and LSD (Local Spin Density) versions of DFT, HF, complete active space and scatteredwave SCF; correlated CI, QC, MO, PES (Potential Energy Surface) coupled-cluster, BornOppenheimer and full-potential LMTO versions of MD (Molecular Dynamics); and other methods, there are reported the key structural and binding parameters of boron clusters calculated or scaled from measured ones: $B_{3}[37,51] ; B_{3}$ and $B_{4}$ in neutral and anionic forms [52]; $\mathrm{B}_{4}$ [53]; $\mathrm{B}_{2}, \mathrm{~B}_{3}$ and $\mathrm{B}_{4}$ [54]; $\mathrm{B}_{5}, \mathrm{~B}_{5}{ }^{+}$and $\mathrm{B}_{5}{ }^{-}$isomers [55]; $\mathrm{B}_{5}{ }^{-}$[56]; $\mathrm{B}_{6}$ and $\mathrm{B}_{6}{ }^{-}$[57]; $\mathrm{B}_{7}$ and $\mathrm{B}_{7}{ }^{-}$[58]; $\mathrm{B}_{2}{ }^{+}-\mathrm{B}_{8}{ }^{+}$[59]; $\mathrm{B}_{n}$ with $n=2-8$ in both the neutral and cationic states [60]; $\mathrm{B}_{n}$ clusters with $4 \leq n \leq 8$ [61]; 8- and 9-atom boron clusters [62]; small boron clusters with up to 10 atoms [63]; $\mathrm{B}_{2-12}$ and $\mathrm{B}_{2-12}{ }^{+}$[64]; small neutral $\mathrm{B}_{n}$ clusters with $n=2-12$ [30]; icosahedral cluster $\mathrm{B}_{12}$ [65]; $\mathrm{B}_{12}[66,67] ; \mathrm{B}_{2}{ }^{+}-\mathrm{B}_{13}{ }^{+}$[68] (see also Reference [69]); multicharged clusters $\mathrm{B}_{n}$ with $n=2-13$ [70]; set of small-sized neutral $\mathrm{B}_{n}$ and anionic $\mathrm{B}_{n}{ }^{-}$boron clusters with $n=5-13$ [31]; $\mathrm{B}_{7}, \mathrm{~B}_{10}$ and $\mathrm{B}_{13}$ [71]; $\mathrm{B}_{12}$ and $\mathrm{B}_{13}$ for neutrals and cations [72]; $\mathrm{B}_{12}{ }^{+}$and $\mathrm{B}_{13}{ }^{+}$[73]; $\mathrm{B}_{12}$ and $\mathrm{B}_{13}{ }^{+}$[74]; isomers of boron 13-clusters [75]; cationic, neutral and anionic charge states of $\mathrm{B}_{13}$ [76]; planar or quasi-planar structures of $\mathrm{B}_{13}, \mathrm{~B}_{13}{ }^{+}$and $\mathrm{B}_{13}{ }^{-}$[77]; isomers of planar boron cluster $\mathrm{B}_{13}$ [78]; small cationic clusters $\mathrm{B}_{n}{ }^{+}$with $n=2-14$ [79]; $\mathrm{B}_{n}$ with $n=2-14$ [80,81]; $\mathrm{B}_{n}$ clusters for $n \leq 14$ [82]; $\mathrm{B}_{n}$ with $n=5-14$ [83]; boron clusters 
in the 10- to 15-atom size range [84]; $\mathrm{B}_{16}{ }^{-}$and $\mathrm{B}_{16}{ }^{2-}$ [85]; $\mathrm{B}_{19}{ }^{-}$[86]; neutral and anionic $\mathrm{B}_{20}$ isomers [87]; $\mathrm{B}_{23}{ }^{+}$[88]; isomers of 24-atom boron cluster [89]; $\mathrm{B}_{25}{ }^{-}$[90]; $\mathrm{B}_{27}{ }^{-}$[91]; $\mathrm{B}_{n}$ with $n=26-29$ in both neutral and anionic states [32]; $\mathrm{B}_{32}$ [92]; $\mathrm{B}_{36}$ and $\mathrm{B}_{36}{ }^{-}[93,94] ; \mathrm{B}_{41}{ }^{-}$ and $\mathrm{B}_{42}{ }^{-}$[95]; neutral $\mathrm{B}_{n}$ clusters with $n=31-50$ [33]; and boron cluster-families: spheres, double-rings and quasi-planars containing up to $n=122$ atoms [96].

\subsection{Applications}

The unique behaviors of clusters of elemental boron have been identified: they react readily with metal surfaces; bond covalently to metal atoms; and cover surfaces with a boron-enriched hard, smooth and corrosion-resistant layer, which can be called nano-boron coating. Some parameters, especially feeding gas concentration, substrate temperature and input power, were optimized [97] to prepare high-pure boron $(94 \% \mathrm{~B})$ coating films by plasma-assisted CVD (Chemical Vapor Deposition). However, due to its thermal resilience, elemental boron is a difficult material to work with. To overcome this problem, Becker perfected a technique for generating clusters of elemental boron in plasma [98]. Unique tribological applications and scalability of boron-rich materials are likely to emerge from the combination of high mechanical strength, chemical stability, exceptional hardness and toughness, wear resistance, strong binding to substrates, low density and other promising physical-chemical properties [99].

The durability of boron coatings in sliding friction has been mentioned [100]. In the search ways to enhance the surface hardness of aluminum, the equilibrium structure, stability, elastic properties and formation dynamics of a boron-enriched surface were studied by using DFT [101]. Nano-indentation simulations suggested that the presence of boron nanostructures in the subsurface region significantly enhances the mechanical hardness of aluminum surfaces.

Boron is the only practical solid material with both volumetric and gravimetric energy densities substantially greater than those of hydrocarbons. That is why boron powder is attractive as a fuel or a supplement in propellants and explosives and potential source of secondary energy generation as well. One study [102] aimed to obtain the energy from elemental boron burning as solid fuel, which is synthesized from boron minerals. By experimental investigation [103] of the combustion characteristics of boron nanoparticles in the post-flame region, a two-stage combustion phenomenon was observed. The extended combustion model for single boron particles of sizes relevant for ramjet chambers was introduced [104] and validated [105]; it comprised a consistent formulation of the heat and mass transfer processes in the boron particles' environment. A review on boron powders given in Reference [106] serves as the basis for research on the tendency of nanosized boron particles to group in an oscillating flow and its effect on the combustion process, flame characteristics and pollutants' emission. Nanoboron can be considered as a superior rocket fuel because nano-particles have almost fluid-like properties. To optimize the reactive surface for combustion, nanoparticle size could be shrunk to clusters consisting of several atoms each. One review paper [107] encompassed the status and challenges in the synthesis process of boron nanoparticles, their dispersion and stability of in liquid hydrocarbon fuels, ignition and combustion characteristics of boron loaded liquid fuel, particle combustion and characterization of post-combustion products. The combustion characteristics of nanofluid fuels containing additions of boron and iron particles together were investigated in Reference [108]. Furthermore, mechanical milling was used to prepare a boron-based composite powder containing $5 \mathrm{wt} . \%$ nanoiron to behave as a catalyst of boron oxidation [109]. The energy density of reactive metal fuel containing $\mathrm{Ti}, \mathrm{Al}$ and $\mathrm{B}$ nanopowders was optimized [110] by varying the Ti:Al:B ratio.

As for information about oxidation of boron clusters, the cross-sections for ionic products formed in reactions of $\mathrm{B}_{1-13}{ }^{+}$with oxygen were measured under single collision conditions [111] and three main reaction mechanisms found to be important: oxidative fragmentation, collision induced dissociation and boron atom abstraction. Cross-sections for oxidation reactions of $\mathrm{CO}_{2}$ with boron cluster ions $\mathrm{B}_{1-14}{ }^{+}$were reported as a function of 
collision energy [112]. At least in some cases, oxidation causes structural rearrangement of the boron clusters. To rationally design and explore a future energy source based on the highly exothermic oxidation of boron, DFT was used to characterize small boron clusters with $0-3$ oxygen atoms and, in total, up to 10 atoms [63].

Thin coatings made from the ${ }^{10} \mathrm{~B}$ isotopically enriched nanoboron providing the highest possible concentration of neutron capture centers can greatly simplify the problem of protection against thermal neutron irradiation [113-115], as well as neutron-fluence nanosensors [116,117]. Boron 2D metallic crystal is a prospective electromagnetic shielding nanomaterial as well [118], so nanoboron can combine neutron and electromagnetic shielding properties.

Reference [119] presented the concept that an elongated planar boron cluster can serve as a "tank tread" at the sub-nanometer scale, a novel propulsion system for potential nanomachines. Ferromagnetism in all-boron planar clusters, e.g., in $\mathrm{B}_{34}$, has been revealed theoretically [120]. They can be assembled to construct all-boron ferromagnetic monolayers, in which ferromagnetism-paramagnetism and semiconductor-metal transitions are expected to occur around $500 \mathrm{~K}$, indicating their potential applications in nanoelectronic and spintronic devices at room temperature.

The recent review [121] on borophene potential applications discusses in detail its other utilizations, such as alkali metal ion and $\mathrm{Li}-\mathrm{S}$ batteries, hydrogen storage, supercapacitors, sensor and catalytic in hydrogen evolution, oxygen reduction and evolution and $\mathrm{CO}_{2}$ electroreduction reaction.

The hierarchy of clusters relative stability / formation probability mainly (together with peculiarities characteristic of formation kinetics) is determined by the cluster-specific binding energy -its binding energy per atom. This work is focused on theoretical estimation of this key energy parameter for boron small planar clusters in frames of recently modified phenomenological diatomic molecular model.

\section{Methodology}

Specific binding energy or binding energy per chemical formula unit of the substance clustered form serves for important factor determining relative stabilities and, consequently, affects the relative concentrations of clusters with different numbers of formula units synthesized during a formation process (of course, the mentioned concentrations are influenced by the process kinetics as well). Here, we intend to calculate specific binding energies for boron small clusters in (quasi)planar structures, starting from the old diatomic model [122] of bounded multi-atomic structures.

The diatomic model is based on the saturation property of interatomic bonding. In its initial approximation, when binding energy is the sum of energies of pair interactions between only neighboring in the structure atoms, the microscopic theory of expansion allows for the quite correct estimation of the thermal expansion coefficient for crystals [123]. Despite its simplicity, the diatomic model has been successfully used to calculate some other anharmonic effects in solids as well [124].

As for the clusters binding energy, to the best our knowledge, there are no reports on its calculations within diatomic model, unless our previous estimates of small all-boron (quasi)planar clusters relative stabilities [125-128] and also their dipole moments [129,130]. These results have been summarized in the mini-reviews [131,132]. Furthermore, the problem was specially analyzed [133] for the three most abundant clusters, namely $B_{11}, B_{12}$ and $\mathrm{B}_{13}$, in different charge states, while taking into account ionization processes.

As is mentioned above, boron (quasi)planar clusters are of special interest, as they can form a borophene-monatomic boron layer with unique properties. The B-B bond length value obtained for boron finite planar clusters in quasi-classical approximation was used for an input parameter in quasi-classical calculations of electron energy band surfaces and DoS (Density-of-State) for a flat boron sheet with a perfect (i.e., without any type of holes) triangular network [134]. It is expected to have metallic properties. The Fermi curve of the boron flat sheet is found consist of 6 parts of 3 closed curves well-approximated by 
ellipses and then representing the quadric energy dispersion of the conduction electrons. The effective mass of electrons at the Fermi level is found to be too small compared with the free electron mass and highly anisotropic. The low effective mass of conduction electrons indicates their high mobility and, hence, high conductivity of the boron sheet.

Recently, we introduced [135] the most general formulation of the diatomic model allowing analytical calculation of the clusters binding energy. It is based on the following assumptions:

- Cluster binding energy is the sum of energies of pair interactions between nearest neighboring in its structure atoms;

- Assuming that relative deviations of bond lengths in the multi-atomic cluster structure from their values in corresponding diatomic molecules are small, pair interaction energies between neighboring atoms are approximated by their quadratic functions;

- Valence-electron-density-redistribution-related corrections to the bond energies in the cluster can be expressed through effective static charges localized on pairs of nearest neighboring atoms;

- Interatomic vibrations related corrections can be approximated by ground-state vibrational energies of corresponding diatomic molecules.

In the simplest but of practical interest special case, when all the bond lengths can be assumed to be almost equal each to other, $a$, cluster symmetry does not lead to any constrain (a relation to be satisfied by bond lengths), and most of other characteristics of valence bonding are equal each to other as well: $a_{0}$ is the bond length corresponding to diatomic molecule, $E_{0}$ is the diatomic molecule binding/dissociation energy, $\omega$ is the cyclic frequency of relative interatomic vibrations and $\mathrm{M}$ is the reduced mass of the pair of atoms with masses $\mu_{1}$ and $\mu_{2}$ constituting the bond:

$$
\frac{1}{\mathrm{M}}=\frac{1}{\mu_{1}}+\frac{1}{\mu_{2}}
$$

In case of identical atoms, we have the following:

$$
\mu_{1}=\mu_{2} \equiv \mu
$$

and

$$
\mathrm{M}=\frac{\mu}{2}
$$

However, effective atomic charge numbers $Z_{i 1}$ and $Z_{i 2}$ characterizing electrostatic correction to the valence bonding energy remain different. The point is that the static charges localized on the pair of nearest-neighboring atoms differ for pairs placed at the center and periphery of the cluster, which is a finite structure of atoms. Here, the $i$ index is as follows:

$$
i=1,2,3, \ldots, k
$$

where the numbers are different types of chemical bonds presented in the cluster, and $k$ denotes their total number. If $N_{i}$ is the number of bonds of $i$-type, then we have the following:

$$
N=\sum_{i=1}^{i=k} N_{i}
$$

which is the number of bonds in whole the cluster.

When we introduce the following parameter,

$$
\mathrm{Z}=\sum_{i=1}^{i=k} N_{i} Z_{i 1} Z_{i 2}
$$


equilibrium bonds length, $a$, and corresponding cluster binding energy, $E$ (in Gauss units), are as follows:

$$
a=a_{0}+\frac{2 e^{2} \mathrm{Z}}{\mu \omega^{2} a_{0}^{2} N}
$$

and

$$
E=\left(E_{0}-\frac{\hbar \omega}{2}\right) N-\frac{e^{2} Z}{a_{0}}+\frac{e^{4} Z^{2}}{\mu \omega^{2} a_{0}^{4} N}
$$

respectively.

From the data available [39] for diboron molecule, $a_{0} \approx 1.590 \AA, E_{0} \approx 3.02 \mathrm{eV}$ and $\omega \approx 1051.3 \mathrm{~cm}^{-1}$ and boron atomic mass weighted for stable isotopes $\left({ }^{10} \mathrm{~B}\right.$ and $\left.{ }^{11} \mathrm{~B}\right)$ natural abundance $\mu \approx 10.811 \mathrm{amu}$, we get the following formula for numerical calculations:

$$
E[\mathrm{eV}] \approx 2.995 \mathrm{~N}-9.053 \mathrm{Z}+\frac{0.7273 \mathrm{Z}^{2}}{N}
$$

The specific binding energy for cluster of $n$ atoms is calculated as $E / n$.

To know parameter $Z$, one needs the estimates of effective atomic charges in the cluster. Below, they are found based on the assumption that the effective number of outer valence shell electrons localized on a given atomic site is proportional to its coordination number. Every neutral boron atom contains only 1 electron in the outer valence shell ( $2 p$-state). Then their total number in the all-boron cluster $\mathrm{B}_{n}$ is given as follows:

$$
v= \begin{cases}n & \mathrm{~B}_{n}^{0} \\ n-1 & \mathrm{~B}_{n}^{+} \\ n+1 & \mathrm{~B}_{n}^{-}\end{cases}
$$

Moreover, if $C_{j}$ denotes the coordination number of $j$-site, then we have the following:

$$
Z_{j} \approx 1-\frac{v C_{j}}{\sum_{l=1}^{l=n} C_{l}}
$$

\begin{tabular}{|c|c|c|c|c|c|c|c|c|c|c|c|}
\hline \multirow{2}{*}{$\begin{array}{l}\text { Number of } \\
\text { Atoms } n\end{array}$} & \multirow{2}{*}{ Structure } & \multirow{2}{*}{$\begin{array}{l}\text { Number of } \\
\text { Bonds } N\end{array}$} & \multirow{2}{*}{$\begin{array}{l}\text { Charge } \\
\text { State }\end{array}$} & \multicolumn{5}{|c|}{$\begin{array}{c}\text { Charge Numbers in Dependence } \\
\text { on Coordination Number }\end{array}$} & \multirow[t]{2}{*}{ Parameter Z } & \multirow{2}{*}{$\begin{array}{c}\text { Specific } \\
\text { Binding } \\
\text { Energy } E / n, \mathrm{eV}\end{array}$} & \multirow{2}{*}{$\begin{array}{c}\text { Bonds } \\
\text { Length, } a,\end{array}$} \\
\hline & & & & 1 & 2 & 3 & 4 & 6 & & & \\
\hline \multirow{3}{*}{2} & \multirow{3}{*}{$0-0$} & \multirow{3}{*}{1} & $\mathrm{~B}_{2}{ }^{0}$ & 0 & & & & & 0 & 1.48 & 1.59 \\
\hline & & & $\mathrm{B}_{2}{ }^{+}$ & $+\frac{1}{2}$ & & & & & +0.2500 & 0.37 & 1.65 \\
\hline & & & $\mathrm{B}_{2}^{-}$ & $-\frac{1}{2}$ & & & & & +0.2500 & 0.37 & 1.65 \\
\hline \multirow{3}{*}{3} & \multirow{3}{*}{ g-o } & \multirow{3}{*}{3} & $\mathrm{~B}_{3}{ }^{0}$ & & 0 & & & & 0 & 2.96 & 1.59 \\
\hline & & & $\mathrm{B}_{3}{ }^{+}$ & & $+\frac{1}{3}$ & & & & +0.3333 & 1.96 & 1.62 \\
\hline & & & $\mathrm{B}_{3}^{-}$ & & $-\frac{1}{3}$ & & & & +0.3333 & 1.96 & 1.62 \\
\hline \multirow{3}{*}{4} & & \multirow{3}{*}{5} & $\mathrm{~B}_{4}{ }^{0}$ & & $+\frac{1}{5}$ & $-\frac{1}{5}$ & & & -0.1200 & 3.97 & 1.58 \\
\hline & & & $\mathrm{B}_{4}{ }^{+}$ & & $+\frac{2}{5}$ & $+\frac{1}{10}$ & & & +0.1700 & 3.31 & 1.60 \\
\hline & & & $\mathrm{B}_{4}^{-}$ & & 0 & $-\frac{1}{2}$ & & & +0.2500 & 3.13 & 1.60 \\
\hline \multirow{3}{*}{5} & \multirow{3}{*}{$8-8$} & \multirow{3}{*}{7} & $\mathrm{~B}_{5}{ }^{0}$ & & $+\frac{2}{7}$ & $-\frac{1}{14}$ & $-\frac{3}{7}$ & & -0.2194 & 4.54 & 1.58 \\
\hline & & & $\mathrm{B}_{5}{ }^{+}$ & & $+\frac{3}{7}$ & $+\frac{1}{7}$ & $-\frac{1}{7}$ & & -0.0204 & 4.17 & 1.59 \\
\hline & & & $\mathrm{B}_{5}^{-}$ & & $+\frac{1}{7}$ & $-\frac{2}{7}$ & $-\frac{5}{7}$ & & +0.2041 & 3.77 & 1.60 \\
\hline
\end{tabular}

The numerical values of these effective charge numbers and a summary of them for parameter $\mathrm{Z}$ for the ground-state structures of boron planar clusters with $n=2-15$ atoms in three charge states are shown below in Table 1.

Table 1. Specific binding energy of boron small planar clusters calculated in diatomic model. 
Table 1. Cont.

\begin{tabular}{|c|c|c|c|c|c|c|c|c|c|c|c|}
\hline \multirow{2}{*}{$\begin{array}{l}\text { Number of } \\
\text { Atoms } n\end{array}$} & \multirow{2}{*}{ Structure } & \multirow{2}{*}{$\begin{array}{l}\text { Number of } \\
\text { Bonds } N\end{array}$} & \multirow{2}{*}{$\begin{array}{l}\text { Charge } \\
\text { State }\end{array}$} & \multicolumn{5}{|c|}{$\begin{array}{c}\text { Charge Numbers in Dependence } \\
\text { on Coordination Number }\end{array}$} & \multirow[t]{2}{*}{ Parameter Z } & \multirow{2}{*}{$\begin{array}{c}\text { Specific } \\
\text { Binding } \\
\text { Energy } E / n, \mathrm{eV}\end{array}$} & \multirow{2}{*}{$\begin{array}{c}\text { Bonds } \\
\text { Length, } a \text {, } \\
\AA\end{array}$} \\
\hline & & & & 1 & 2 & 3 & 4 & 6 & & & \\
\hline \multirow{3}{*}{6} & & \multirow{3}{*}{9} & $\mathrm{~B}_{6}{ }^{0}$ & & $+\frac{1}{3}$ & & $-\frac{1}{3}$ & & -0.3333 & 4.94 & 1.58 \\
\hline & & & $\mathrm{B}_{6}{ }^{+}$ & & $+\frac{4}{9}$ & & $-\frac{1}{9}$ & & -0.2593 & 4.82 & 1.58 \\
\hline & & & $\mathrm{B}_{6}^{-}$ & & $+\frac{2}{9}$ & & $-\frac{5}{9}$ & & +0.1852 & 4.15 & 1.60 \\
\hline \multirow{3}{*}{7} & & \multirow{3}{*}{12} & $\mathrm{~B}_{7}^{0}$ & & & $+\frac{1}{8}$ & & $-\frac{3}{4}$ & -0.4688 & 5.67 & 1.58 \\
\hline & & & $\mathrm{B}_{7}^{+}$ & & & $+\frac{1}{4}$ & & $-\frac{1}{2}$ & -0.3750 & 5.55 & 1.58 \\
\hline & & & $\mathrm{B}_{7}^{-}$ & & & 0 & & -1 & 0 & 5.07 & 1.59 \\
\hline \multirow{3}{*}{8} & & \multirow{3}{*}{14} & $\mathrm{~B}_{8}{ }^{0}$ & & $+\frac{3}{7}$ & $+\frac{1}{7}$ & $-\frac{1}{7}$ & $-\frac{5}{7}$ & -0.2857 & 5.50 & 1.59 \\
\hline & & & $\mathrm{B}_{8}{ }^{+}$ & & $+\frac{1}{2}$ & $+\frac{1}{4}$ & 0 & $-\frac{1}{2}$ & -0.3125 & 5.53 & 1.58 \\
\hline & & & $\mathrm{B}_{8}^{-}$ & & $+\frac{5}{14}$ & $+\frac{1}{28}$ & $-\frac{2}{7}$ & $-\frac{13}{14}$ & +0.2589 & 4.88 & 1.60 \\
\hline \multirow{3}{*}{9} & & \multirow{3}{*}{16} & $\mathrm{~B}_{9}{ }^{0}$ & & $+\frac{7}{16}$ & $+\frac{5}{32}$ & $-\frac{1}{8}$ & $-\frac{11}{16}$ & +0.2500 & 5.00 & 1.59 \\
\hline & & & $\mathrm{B}_{9}{ }^{+}$ & & $+\frac{1}{2}$ & $+\frac{1}{4}$ & 0 & $-\frac{1}{2}$ & 0 & 5.25 & 1.59 \\
\hline & & & $\mathrm{B}_{9}^{-}$ & & $+\frac{3}{8}$ & $+\frac{1}{16}$ & $-\frac{1}{4}$ & $-\frac{7}{8}$ & +1.0000 & 4.25 & 1.61 \\
\hline \multirow{3}{*}{10} & & \multirow{3}{*}{19} & $\mathrm{~B}_{10}{ }^{0}$ & & & $+\frac{4}{19}$ & $-\frac{1}{19}$ & $-\frac{11}{19}$ & -0.3850 & 5.96 & 1.59 \\
\hline & & & $\mathrm{B}_{10}{ }^{+}$ & & & $+\frac{11}{38}$ & $+\frac{1}{19}$ & $-\frac{8}{19}$ & -0.2465 & 5.84 & 1.59 \\
\hline & & & $\mathrm{B}_{10^{-}}$ & & & $+\frac{5}{38}$ & $-\frac{3}{19}$ & $-\frac{14}{19}$ & +0.4127 & 5.24 & 1.60 \\
\hline \multirow{3}{*}{11} & & \multirow{3}{*}{21} & $\mathrm{~B}_{11}{ }^{0}$ & & $+\frac{10}{21}$ & $+\frac{9}{42}$ & $-\frac{1}{21}$ & $-\frac{4}{7}$ & +0.0102 & 5.63 & 1.59 \\
\hline & & & $\mathrm{B}_{11}^{+}$ & & $+\frac{11}{21}$ & $+\frac{2}{7}$ & $+\frac{1}{21}$ & $-\frac{3}{7}$ & +0.2381 & 5.45 & 1.59 \\
\hline & & & $\mathrm{B}_{11}^{-}$ & & $+\frac{3}{7}$ & $+\frac{1}{7}$ & $-\frac{1}{7}$ & $-\frac{5}{7}$ & -0.7143 & 6.23 & 1.58 \\
\hline \multirow{3}{*}{12} & & \multirow{3}{*}{24} & $\mathrm{~B}_{12}{ }^{0}$ & & & $+\frac{1}{4}$ & 0 & $-\frac{1}{2}$ & +0.1875 & 5.77 & 1.59 \\
\hline & & & $\mathrm{B}_{12}{ }^{+}$ & & & $+\frac{5}{16}$ & $+\frac{1}{12}$ & $-\frac{3}{8}$ & -0.3125 & 6.15 & 1.59 \\
\hline & & & $\mathrm{B}_{12}{ }^{-}$ & & & $+\frac{3}{16}$ & $-\frac{1}{12}$ & $-\frac{5}{8}$ & +0.2461 & 5.72 & 1.59 \\
\hline \multirow{3}{*}{13} & & \multirow{3}{*}{26} & $\mathrm{~B}_{13}{ }^{0}$ & & & $+\frac{1}{4}$ & 0 & $-\frac{1}{2}$ & -0.5000 & 6.26 & 1.59 \\
\hline & & & $\mathrm{B}_{13}{ }^{+}$ & & & $+\frac{4}{13}$ & $+\frac{1}{13}$ & $-\frac{5}{13}$ & -0.1657 & 6.03 & 1.59 \\
\hline & & & $\mathrm{B}_{13}^{-}$ & & & $+\frac{5}{26}$ & $-\frac{1}{13}$ & $-\frac{8}{13}$ & -0.2071 & 6.05 & 1.59 \\
\hline \multirow{3}{*}{14} & & \multirow{3}{*}{28} & $\mathrm{~B}_{14}{ }^{0}$ & & $+\frac{1}{2}$ & $+\frac{1}{4}$ & 0 & $-\frac{1}{2}$ & +0.5625 & 5.55 & 1.60 \\
\hline & & & $\mathrm{B}_{14}^{+}$ & & $+\frac{15}{28}$ & $+\frac{17}{56}$ & $+\frac{1}{14}$ & $-\frac{11}{28}$ & +0.0590 & 5.87 & 1.59 \\
\hline & & & $\mathrm{B}_{14}{ }^{-}$ & & $+\frac{13}{28}$ & $+\frac{11}{56}$ & $-\frac{1}{14}$ & $-\frac{17}{28}$ & +1.6151 & 4.87 & 1.61 \\
\hline \multirow{3}{*}{15} & & & $\mathrm{~B}_{15}{ }^{0}$ & & $+\frac{1}{2}$ & & 0 & $-\frac{1}{2}$ & +0.7500 & 5.46 & 1.60 \\
\hline & & 30 & $\mathrm{~B}_{15}{ }^{+}$ & & $+\frac{8}{15}$ & & $+\frac{1}{15}$ & $-\frac{2}{5}$ & +0.4133 & 5.66 & 1.59 \\
\hline & & & $\mathrm{B}_{15}{ }^{-}$ & & $+\frac{7}{15}$ & & $-\frac{1}{15}$ & $-\frac{3}{5}$ & +1.4133 & 5.06 & 1.60 \\
\hline
\end{tabular}

\section{Results and Discussion}

Here, we report the specific binding energy that we calculated for boron small planar clusters only in their ground-state structures. Ground-state structural isomers were chosen based on two criteria leading to maximal binding energy: (1) maximum number of bonds and (2) highest symmetry. We calculated clusters containing up to 15 boron atoms, because, for bigger species, 2D (quasi)planar structures are challenged by 3D ring-like structures (actually fragments of nanotubes), which are characteristic for boron clusters at $n \geq 20$.

Specific binding energies calculated in diatomic model for neutral $\mathrm{B}_{n}{ }^{0}$, cationic $\mathrm{B}_{n}{ }^{+}$ and anionic $\mathrm{B}_{n}{ }^{-}$clusters with the number of atom $n=2-15$ are listed in Table 1 and presented in Figure 2. 


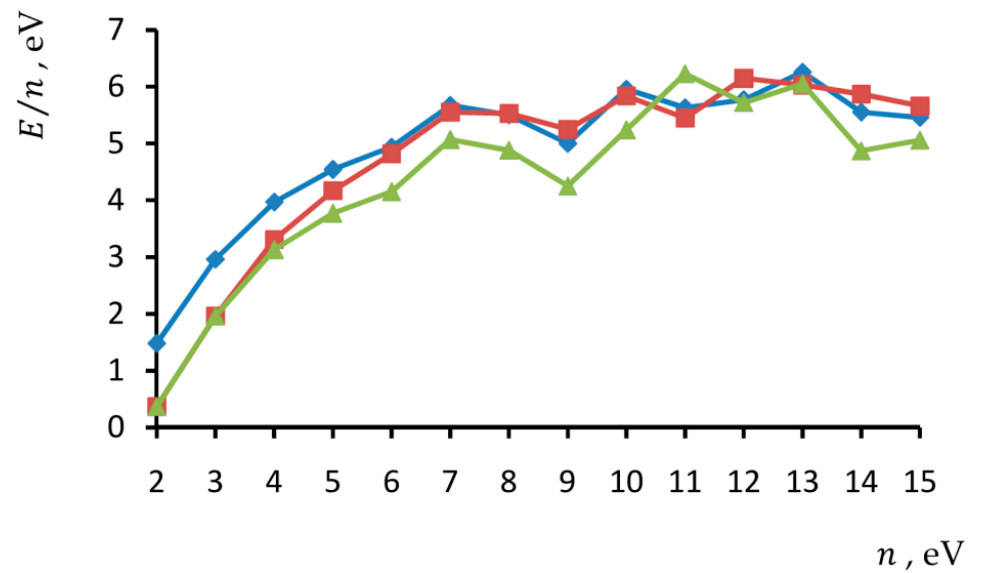

Figure 2. Specific binding energy of neutral $(\boldsymbol{)})$, positively $(\boldsymbol{\square})$ and negatively $(\boldsymbol{\Lambda})$ charged boron small planar clusters in dependence on number of atoms calculated in diatomic model.

For comparison, available experimental data are presented in Figure 3. In Reference [130], clusters in boron vapor were generated by the thermal decomposition of electrode made of a boron-rich metal boride. Note that, in this way, initially clusters are formed in neutral state but then ionized by collisions with released in the chamber energetic electrons and accelerated toward the mass-spectrometer. Boron cluster cations were generated [29] by laser evaporation of target compact made of boron dust with gold added to increase its stability. Here, a disproportionately intense peak related to traces of gold is erased because it masks that of $\mathrm{B}^{+}{ }_{18}$, as masses of gold $\mathrm{Au}$ atom and boron 18-atom cluster are almost undistinguishable. As for the boron cluster anions, they were produced [28] by laser vaporization from homogeneous pure boron target rods.

Again, for comparison, Figure 4 represents the theoretical specific binding energies of small boron clusters (in different, not only in planar, structures) depending on their size calculated by using QC methods [70]. One can note that such a typical curve looks similar to curves obtained in frames of diatomic model.

Thus, from the diatomic model, the theoretical equilibrium binding energies per $\mathrm{B}$ atom and B-B bond lengths are expected within ranges of $0.37-6.26 \mathrm{eV}$ and $1.58-1.65 \AA$, respectively. For the most stabile neutral, positively and negatively charged species, $\mathrm{B}_{13}{ }^{0}$, $\mathrm{B}_{12}{ }^{+}$and $\mathrm{B}_{11}{ }^{-}$are predicted; their characteristics are $6.26,6.15$ and $6.23 \mathrm{eV}$ and $1.59,1.59$ and $1.58 \AA$, respectively.

From experimental reports, the diboron molecule $B_{2}$ dissociation energy is expected within the ranges of 2.58-3.06 [15] and 2.26-3.12 eV [34]. Theoretical values obtained by HF [37], MO [38], CI [40], quasi-classical [41,42] and PES [53] methods are 2.86, 2.71, 2.70$2.78,2.80$ and $2.70 \mathrm{eV}$, respectively. As diboron molecule contains two atoms, the corresponding specific binding energies equal to $(2.58-3.06) / 2=1.29-1.53$ and $(2.26-3.12) / 2=1.13-1.56$ for measured and $2.86 / 2=1.43,2.71 / 2 \approx 1.36,(2.70-2.78) / 2=1.35-1.39,2.80 / 2=1.40$ and $2.70 / 2=1.35 \mathrm{eV}$ for calculated dissociation energies. Calculations based on DFT [30] and QC [70] yielded 1.36 and $1.39 \mathrm{eV}$, respectively. The value of $1.48 \mathrm{eV}$ obtained for cluster $\mathrm{B}_{2}{ }^{0}$ from the diatomic model falls in both experimental ranges and seems only slightly overestimated if compared with previous theoretical ones.

The ground-state dissociation energy of diboron cation $\mathrm{B}_{2}{ }^{+}$calculated with the CI approach [46] is $1.94 \mathrm{eV}$, which corresponds to $1.94 / 2=0.97 \mathrm{eV}$ for specific binding energy, significantly exceeding $0.37 \mathrm{eV}$ yielded by diatomic model for $\mathrm{B}_{2}{ }^{+}$. The same is true for the QC specific binding energy for $\mathrm{B}_{2}{ }^{+}: 1.16 \mathrm{eV}$ [70]. This discrepancy should be related not only to the diatomic model itself but mainly phenomenological estimation of static atomic charges used. The point is that, when calculating static atomic charges in diatomic species, the equal dividing of a single elemental charge between constituent atoms is too crude of an approximation, leading to the overestimated Coulomb repulsive energy. SCF CI [69] and calibrated hybrid DFT [82] approaches' $\mathrm{B}_{2}{ }^{+} \rightarrow \mathrm{B}_{1}{ }^{+}+\mathrm{B}_{1}{ }^{0}$ fragmentation energies are 1.47 
and $1.96 \mathrm{eV}$, respectively. The corresponding specific binding energies are $1.47 / 2 \approx 0.74$ and $1.96 / 2=0.98 \mathrm{eV}$.

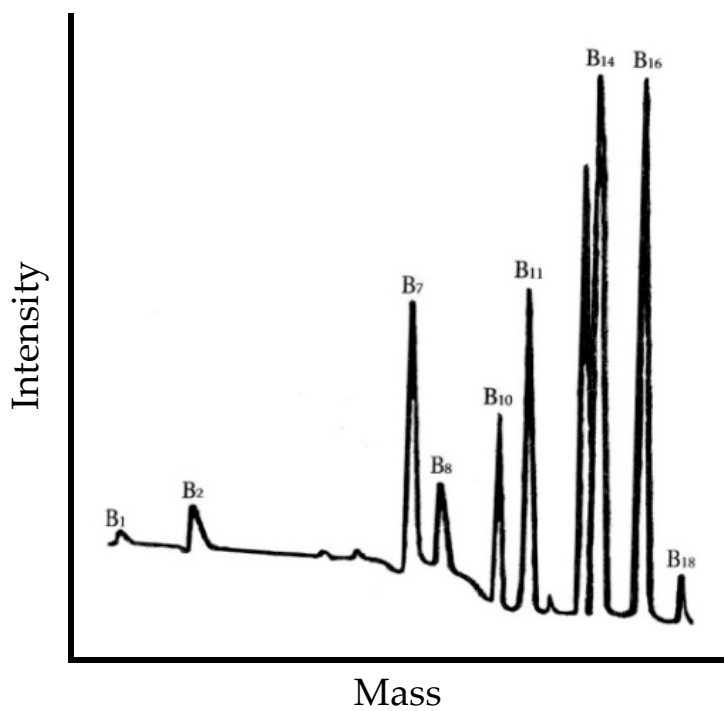

(a)

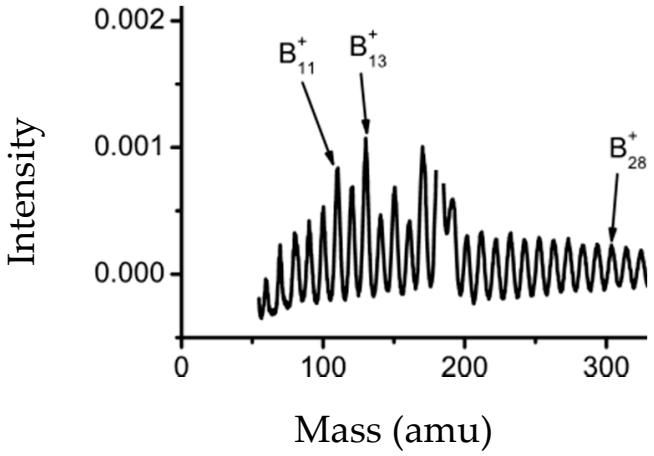

(b)

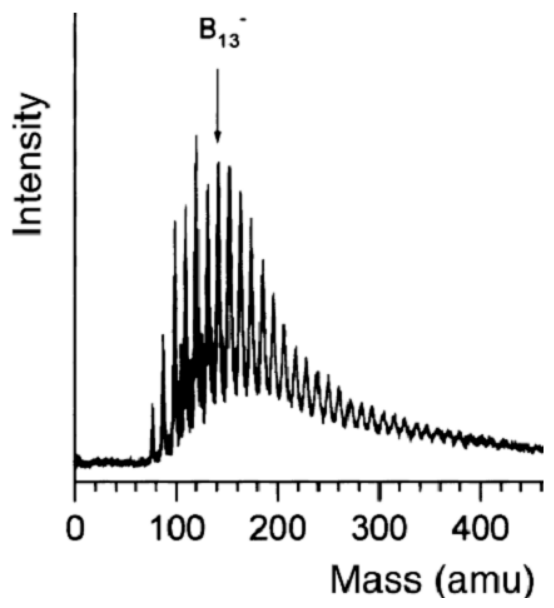

(c)

Figure 3. Experimentally recorded mass spectra of (a) neutral [130], Copyright (2015), with permission from Authors; (b) positively [29], Copyright (2010), with permission from KIT Scientific Publishing; and (c) negatively charged [28] boron clusters, Copyright (2003), with permission from Elsevier. 


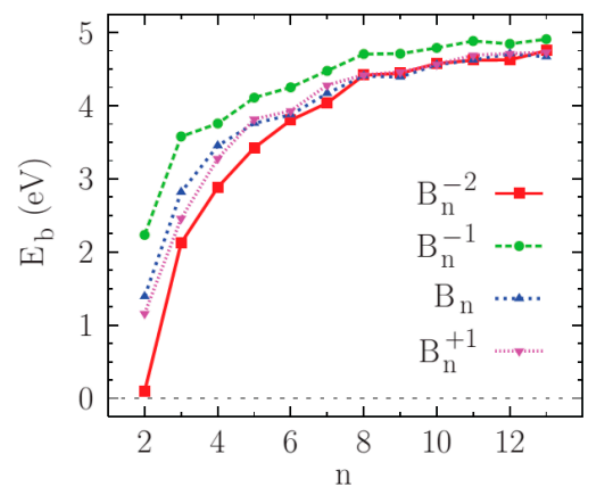

Figure 4. Binding energy per atom of neutral and ionized boron clusters as function of size [70], Copyright (2011), with permission from American Physical Society.

The QC specific binding energy of anionic cluster $\mathrm{B}_{2}{ }^{-}$is $2.24 \mathrm{eV}$ [70]. As for the cationic cluster, this value significantly exceeds $0.37 \mathrm{eV}$, which is suggested by the diatomic model. The reason should be the same as for cationic isomer.

For the $\mathrm{B}_{3}$ cluster, the HF scaled dissociation energy is $8.59 \mathrm{eV}$ [37], while the PES study showed that atomization energy for $\mathrm{B}_{3}$ would be in the range of 8.21-8.36 eV [53]. As the molecule contains three atoms, the corresponding specific binding energies are equal to $8.59 / 3 \approx 2.86$ and $(8.21-8.36) / 3 \approx 2.74-2.79 \mathrm{eV}$, respectively. Calculations based on DFT [30] and QC [70] approaches yielded 2.76 and $2.82 \mathrm{eV}$, respectively. The diatomic model'svalue of $2.96 \mathrm{eV}$ for cluster $\mathrm{B}_{3}{ }^{0}$ again seems to be slightly overestimated if compared with other theoretical results.

The QC specific binding energy of $\mathrm{B}_{3}{ }^{+}$and $\mathrm{B}_{3}{ }^{-}$clusters is 2.46 and $3.58 \mathrm{eV}$, respectively [70], while the diatomic model gives $1.96 \mathrm{eV}$ for both clusterions.

A SCF calculation [51] predicted that the energy of fragmentation of the $\mathrm{B}_{3}$ cluster to produce diatomic $B_{2}$ and atomic $B$ is $4.96 \mathrm{eV}$. From the diatomic model, one obtains $3 \times 2.96-2 \times 1.48=5.92 \mathrm{eV}$.

The SCF CI B ${ }_{3}^{+} \rightarrow \mathrm{B}_{1}{ }^{+}+\mathrm{B}_{2}{ }^{0}$ and $\mathrm{B}_{3}{ }^{+} \rightarrow \mathrm{B}_{2}{ }^{+}+\mathrm{B}_{1}{ }^{0}$ fragmentation energies are 1.45 and $2.00 \mathrm{eV}$, respectively [68], while the $\mathrm{B}_{3}{ }^{+} \rightarrow \mathrm{B}_{1}{ }^{+}+\mathrm{B}_{2}{ }^{0}$ fragmentation energy calibrated in a hybrid DFT approach is $4.33 \mathrm{eV}$ [82]. The diatomic model gives $3 \times 1.96-2 \times 0.37=5.14$ and $3 \times 1.96-2 \times 1.48=2.92 \mathrm{eV}$ for $\mathrm{B}_{3}{ }^{+} \rightarrow \mathrm{B}_{1}{ }^{+}+\mathrm{B}_{2}{ }^{0}$ and $\mathrm{B}_{3}{ }^{+} \rightarrow \mathrm{B}_{2}{ }^{+}+\mathrm{B}_{1}{ }^{0}$ reactions, respectively.

According to the study of the $\mathrm{B}_{4}$ cluster PES, its total atomization energy is expected in the range of 13.46-13.64 eV [53]. As this cluster consists of four atoms, the corresponding specific binding energy is (13.46-13.64)/ $4 \approx 3.37-3.41 \mathrm{eV}$. The calculations based on DFT [30] and QC [70] approaches yielded 3.37 and $3.45 \mathrm{eV}$, respectively. The value of $3.97 \mathrm{eV}$ obtained in the diatomic model for the neutral $\mathrm{B}_{4}{ }^{0}$ cluster is higher but comparable. However, the $\mathrm{CI}$ analysis of $\mathrm{B}_{4}$ tetramer in rhombus geometry significantly underestimated its specific binding energy: $2.42 \mathrm{eV}$ [54].

The QC specific binding energies of $\mathrm{B}_{4}{ }^{+}$and $\mathrm{B}_{4}{ }^{-}$clusters are 3.28 and $3.76 \mathrm{eV}$, respectively [70]. The diatomic model gives quite close results of 3.31 and $3.13 \mathrm{eV}$ for these cluster-ions.

SCF CI B ${ }^{+} \rightarrow \mathrm{B}_{1}{ }^{+}+\mathrm{B}_{3}{ }^{0}, \mathrm{~B}_{4}{ }^{+} \rightarrow \mathrm{B}_{3}{ }^{+}+\mathrm{B}_{1}{ }^{0}$ and $\mathrm{B}_{4}{ }^{+} \rightarrow \mathrm{B}_{2}{ }^{+}+\mathrm{B}_{2}{ }^{0}$ fragmentation energies are 1.75, 2.80 and 3.20 eV, respectively [68]. Moreover, $\mathrm{B}_{4}{ }^{+} \rightarrow \mathrm{B}_{1}{ }^{+}+\mathrm{B}_{3}{ }^{0}$ fragmentation energy calibrated in a hybrid DFT approach equals to $4.23 \mathrm{eV}$ [82]. In the diatomic approach, their values are $4 \times 3.31-3 \times 2.96=4.36,4 \times 3.31-3 \times 1.96=7.36$ and $4 \times 3.31-2 \times 0.37-$ $2 \times 1.48=9.54$, respectively.

The specific binding energies of the $\mathrm{B}_{5}{ }^{0}$ cluster calculated in DFT [30] and two versions of QC approach [31,70] are 3.67, 3.68 and $3.76 \mathrm{eV}$, respectively. Our result is $4.54 \mathrm{eV}$.

The QC specific binding energy of $\mathrm{B}_{5}{ }^{+}$is $3.82 \mathrm{eV}$ [70], while we obtained $4.17 \mathrm{eV}$.

The specific binding energies of the $\mathrm{B}_{5}{ }^{-}$cluster calculated in two versions of the QC approach are 4.04 [31] and $4.11 \mathrm{eV}$ [70], respectively, while the diatomic model yields the lower value of $3.77 \mathrm{eV}$. 
The SCF CI B ${ }_{5}^{+} \rightarrow \mathrm{B}_{1}{ }^{+}+\mathrm{B}_{4}{ }^{0}$ fragmentation energy is $2.00 \mathrm{eV}$ [68]. By calibrating this energy in a hybrid DFT approach, it was found $4.95 \mathrm{eV}$ [82] to be in almost perfect agreement with the diatomic model result of $5 \times 4.17-4 \times 3.97=4.97 \mathrm{eV}$.

By using DFT [30], QC [31,70] and diatomic model (this work) methods, we calculated the specific binding energy for the $\mathrm{B}_{6}{ }^{0}$ cluster as $3.79,3.84,3.88$ and $4.94 \mathrm{eV}$, respectively. The QC approach [70] and diatomic model have yielded specific binding energy for $\mathrm{B}_{6}{ }^{+}$cluster as 3.93 and $4.83 \mathrm{eV}$, respectively. According to two QC [31,70] and diatomic model calculations, the specific binding energy for $\mathrm{B}_{6}{ }^{-}$cluster is $4.16,4.25$ and $4.15 \mathrm{eV}$, respectively.

The SCF CI B ${ }_{6}{ }^{+} \rightarrow \mathrm{B}_{5}{ }^{+}+\mathrm{B}_{1}{ }^{0}$ fragmentation energy is $2.20 \mathrm{eV}$ [68], while, in a hybrid DFT approach, it is found to be $4.11 \mathrm{eV}$ [82]. The diatomic value of $6 \times 4.82-5 \times 4.17=8.07 \mathrm{eV}$ exceeds both of them.

DFT [30], QC [31,70], LMTO MD [71] and diatomic model specific binding energies for the $\mathrm{B}_{7}{ }^{0}$ cluster are $4.07,4.11,4.17,5.24$ and $5.67 \mathrm{eV}$, respectively. For the $\mathrm{B}_{7}{ }^{+}$cluster, the QC [70] and diatomic-model specific binding energies are 4.28 and $5.55 \mathrm{eV}$, respectively. Moreover, the QC $[31,70]$ and diatomic-model specific binding energies for $\mathrm{B}_{7}{ }^{-}$cluster are $4.49,4.48$ and $5.07 \mathrm{eV}$, respectively.

The $\mathrm{B}_{7}{ }^{+} \rightarrow \mathrm{B}_{6}{ }^{+}+\mathrm{B}_{1}{ }^{0}$ fragmentation energy calibrated in a hybrid DFT approach is $6.05 \mathrm{eV}$ [82], i.e., lower than that predicted by the diatomic model: $7 \times 5.55-6 \times 4.82=9.93 \mathrm{eV}$.

For the $\mathrm{B}_{8}{ }^{0}$ cluster, the DFT [30], QC [31,70] and diatomic-model specific binding energies are 4.31, 4.33, 4.41 and $5.50 \mathrm{eV}$, respectively. As for the $\mathrm{B}_{8}{ }^{+}$cluster, its $\mathrm{QC}$ [70] and diatomic-model specific binding energies are 4.42 and $5.53 \mathrm{eV}$, respectively. Moreover, the $\mathrm{B}_{8}{ }^{-}$cluster's QC [31,70] and diatomic-model specific binding energies equal to $4.71,4.71$ and $4.88 \mathrm{eV}$, respectively.

The $\mathrm{B}_{8}{ }^{+} \rightarrow \mathrm{B}_{7}{ }^{+}+\mathrm{B}_{1}^{0}$ fragmentation energy calibrated in a hybrid DFT approach is $5.04 \mathrm{eV}$ [82], which is in good agreement with this work's calculation: $8 \times 5.53-7 \times$ $5.55=5.39 \mathrm{eV}$.

The DFT [30], QC [70] and diatomic-model specific binding energies of $\mathrm{B}_{9}{ }^{0}$ cluster are 4.30, 4.39 and $5.00 \mathrm{eV}$, respectively. The $\mathrm{QC}$ [70] and diatomic-model specific binding energies of $\mathrm{B}_{9}{ }^{+}$cluster are 4.46 and $5.25 \mathrm{eV}$, respectively. The $\mathrm{QC}[31,70]$ and diatomic-model specific binding energies of $\mathrm{B}_{9}{ }^{-}$cluster are $4.55,4.71$ and $4.25 \mathrm{eV}$, respectively.

The $\mathrm{B}_{9}{ }^{+} \rightarrow \mathrm{B}_{8}{ }^{+}+\mathrm{B}_{1}{ }^{0}$ fragmentation energy calibrated in a hybrid DFT approach is $4.29 \mathrm{eV}$ [82]. The diatomic model yields the fragmentation energy of $9 \times 5.25-8 \times$ $5.53=3.01 \mathrm{eV}$, which is surprisingly less than previous theoretical results.

The DFT [30], QC [70], LMTO MD [71] and diatomic-model specific binding energies of $\mathrm{B}_{10}{ }^{0}$ cluster are $4.45,4.56,5.78$ and $5.96 \mathrm{eV}$, respectively. The QC [70] and diatomic-model specific binding energies of the $\mathrm{B}_{10}{ }^{+}$cluster are 4.57 and $5.84 \mathrm{eV}$, respectively. The $\mathrm{QC}$ [70] and diatomic-model specific binding energies of the $\mathrm{B}_{10}{ }^{-}$cluster are 4.79 and $5.24 \mathrm{eV}$, respectively.

As for the $\mathrm{B}_{10}{ }^{+} \rightarrow \mathrm{B}_{9}{ }^{+}+\mathrm{B}_{1}{ }^{0}$ fragmentation energy calibrated in a hybrid DFT approach, it equals $5.58 \mathrm{eV}$ [82], while the diatomic model gives $10 \times 5.84-9 \times 5.25=11.15 \mathrm{eV}$.

The DFT [30], QC [70] and diatomic-model specific binding energies of the $\mathrm{B}_{11}{ }^{0}$ cluster are 4.52, 4.63 and $5.63 \mathrm{eV}$, respectively. QC [70] and diatomic-model specific binding energies of $\mathrm{B}_{11}{ }^{+}$cluster are 4.69 and $5.45 \mathrm{eV}$, respectively. The QC [70] and diatomic-model specific binding energies of $\mathrm{B}_{11}{ }^{-}$cluster are 4.89 and $6.23 \mathrm{eV}$, respectively.

The $\mathrm{B}_{11}{ }^{+} \rightarrow \mathrm{B}_{10}{ }^{+}+\mathrm{B}_{1}{ }^{0}$ fragmentation energy calibrated in a hybrid DFT approach is $5.18 \mathrm{eV}$ [82]. In this case, the diatomic model value is significantly less: $11 \times 5.45-10 \times$ $5.84=1.55 \mathrm{eV}$.

In Reference [67], the Jahn-Teller distortion mechanism, which transforms the highlysymmetric icosahedral structure $\mathrm{B}_{12}{ }^{0}$ into a quasi-planar disc-like structure with binding energy per atom as $4.60 \mathrm{eV}$, was proposed. The same value was suggested based on DFT calculations: $4.60 \mathrm{eV}$ [30]. The QC specific binding energy of $\mathrm{B}_{12}{ }^{0}$ is $4.71 \mathrm{eV}$ [70], while our diatomic model gives $5.77 \mathrm{eV}$. The QC [70] and diatomic-model specific binding energies of the $\mathrm{B}_{12}{ }^{+}$and $\mathrm{B}_{12}{ }^{-}$charged cluster are 4.72 and 4.85 , and 6.15 and $5.72 \mathrm{eV}$, respectively. 
The $\mathrm{B}_{12}{ }^{+} \rightarrow \mathrm{B}_{11}{ }^{+}+\mathrm{B}_{1}{ }^{0}$ fragmentation energy calibrated in a hybrid DFT approach is $4.64 \mathrm{eV}$ [82], while $12 \times 6.15-11 \times 5.45=13.85 \mathrm{eV}$ is obtained based on diatomic model.

The QC [70], LMTO MD [71] and diatomic-model specific binding energies of the $\mathrm{B}_{13}{ }^{0}$ cluster are 4.67, 5.94 and $6.26 \mathrm{eV}$, respectively. The QC [70] and diatomic-model specific binding energies of the $\mathrm{B}_{13}{ }^{+}$and $\mathrm{B}_{13}{ }^{-}$charged cluster are 4.73 and 4.91 , and 6.03 and $6.05 \mathrm{eV}$, respectively.

The $\mathrm{B}_{13}{ }^{+} \rightarrow \mathrm{B}_{12}{ }^{+}+\mathrm{B}_{1}{ }^{0}$ fragmentation energy calibrated in a hybrid DFT approach is $5.68 \mathrm{eV}$ [82]. The diatomic model gives $13 \times 6.03-12 \times 6.15=4.59 \mathrm{eV}$.

Finally, the $\mathrm{B}_{14}{ }^{+} \rightarrow \mathrm{B}_{13}{ }^{+}+\mathrm{B}_{1}{ }^{0}$ fragmentation energy calibrated in a hybrid DFT approach is $3.96 \mathrm{eV}$ [82], which is in satisfactory agreement with diatomic model value of $14 \times 5.87-13 \times 6.03=3.79 \mathrm{eV}$.

The above comparisons between the diatomic model and the previous results on specific binding and fragmentation energies of small boron clusters are summarized in Tables 2 and 3, respectively. Here, the term "specific fragmentation energy" implies the fragmentation energy per doubled difference between B-B bonds' numbers in the initial cluster (i.e., before fragmenting) and its fragments. For example, specific binding energies (in diatomic model), numbers of $\mathrm{B}$ atoms and $\mathrm{B}-\mathrm{B}$ bonds of clusters $\mathrm{B}_{4}{ }^{+}, \mathrm{B}_{2}{ }^{+}$and $\mathrm{B}_{2}{ }^{0}$ are $3.31,0.37$ and $1.48 \mathrm{eV} ; 4,2$ and 2 ; and 5,1 and 1 , respectively. Then, specific $\mathrm{B}_{4}{ }^{+} \rightarrow \mathrm{B}_{2}{ }^{+}+\mathrm{B}_{2}{ }^{0}$ fragmentation energy is $(4 \times 3.31-2 \times 0.37-2 \times 1.48) /(2 \times(5-1-1))=1.59 \mathrm{eV}$.

Theoretical $E / n-n$ curves obtained in the diatomic model in general features coincide with experimental ones. In particular, we can see maxima in the range $B_{11}-B_{13}$. At a number of atoms $\leq 8$, neutral clusters are predicted to be more stable than their charged isomers. Moreover, at a number of $\leq 9$, cations seem to be more stable than anions. However, at a higher number of atoms in boron planar clusters, there is no common trend of relative stability in the dependence of the charge state. As for the specific bind energy averaged by charge states, it saturates. Discrepancies in details seem to be related to the different kinetics of experimental generation processes of small boron clusters, as well as assumptions of the diatomic method used in theoretical calculations.

As for quantitative agreement in specific binding and fragmentation energies and their dependences on charge states and number of atoms in small boron clusters with previously reported (in the most part theoretical) studies, it also seems satisfactory. However, the diatomic model frequently overestimates these energy characteristics. This could be related to the energy phenomenological parameter-dissociation energy of diboron molecule $\mathrm{B}_{2}$ - used in constructing the diatomic binding energy curve, as it is measured with too significant an error. Of course, such an almost systematic deviation from previous studies partially should be related to their assumptions on cluster structures and applied methods of calculation or measurement errors.

Table 2. Comparison of the literature data on specific binding energies (in $\mathrm{eV}$ ) of boron small clusters with values calculated in diatomic model.

\begin{tabular}{ccc}
\hline Cluster & Literature Data & Diatomic Model \\
\hline & $1.29-1.53[15]$ & \\
& $1.36[30]$ & \\
& $1.13-1.56[34]$ & \\
& $1.43[37]$ & 1.48 \\
$\mathrm{~B}_{2}{ }^{0}$ & $1.36[38]$ & \\
& $1.35-1.39[40]$ & \\
& $1.40[41,42]$ & \\
& $1.35[53]$ & \\
& $1.39[70]$ & 0.37 \\
\hline & $0.97[46]$ & \\
& $0.74[69]$ & \\
\end{tabular}


Table 2. Cont.

\begin{tabular}{|c|c|c|}
\hline Cluster & Literature Data & Diatomic Model \\
\hline \multirow[t]{2}{*}{$\mathrm{B}_{2}^{-}$} & $2.24[70]$ & 0.37 \\
\hline & $2.76[30]$ & \multirow{4}{*}{2.96} \\
\hline \multirow{3}{*}{$\mathrm{B}_{3}$} & $2.86[37]$ & \\
\hline & $2.74-2.79[53]$ & \\
\hline & $2.82[70]$ & \\
\hline $\mathrm{B}_{3}^{+}$ & $2.46[70]$ & 1.96 \\
\hline $\mathrm{B}_{3}^{-}$ & $3.58[70]$ & 1.96 \\
\hline \multirow{4}{*}{$\mathrm{B}_{4}$} & $3.37[30]$ & \multirow{4}{*}{3.97} \\
\hline & $3.37-3.41[53]$ & \\
\hline & $2.42[54]$ & \\
\hline & $3.45[70]$ & \\
\hline $\mathrm{B}_{4}^{+}$ & $3.28[70]$ & 3.31 \\
\hline $\mathrm{B}_{4}^{-}$ & $3.76[70]$ & 3.13 \\
\hline \multirow{3}{*}{$\mathrm{B}_{5}{ }^{0}$} & $3.67[30]$ & \multirow{3}{*}{4.54} \\
\hline & $3.68[31]$ & \\
\hline & $3.76[70]$ & \\
\hline $\mathrm{B}_{5}^{+}$ & $3.82[70]$ & 4.17 \\
\hline \multirow{2}{*}{$\mathrm{B}_{5}^{-}$} & $4.04[31]$ & \multirow{2}{*}{3.77} \\
\hline & $4.11[70]$ & \\
\hline \multirow{3}{*}{$\mathrm{B}_{6}{ }^{0}$} & $3.79[30]$ & \multirow{3}{*}{4.94} \\
\hline & $3.84[31]$ & \\
\hline & $3.88[70]$ & \\
\hline $\mathrm{B}_{6}^{+}$ & $3.93[70]$ & 4.83 \\
\hline \multirow{2}{*}{$\mathrm{B}_{6}^{-}$} & $4.16[31]$ & \multirow{2}{*}{4.15} \\
\hline & $4.25[70]$ & \\
\hline \multirow{4}{*}{$\mathrm{B}_{7}^{0}$} & $4.07[30]$ & \multirow{4}{*}{5.67} \\
\hline & $4.11[31]$ & \\
\hline & $4.17[70]$ & \\
\hline & $5.24[71]$ & \\
\hline $\mathrm{B}_{7}^{+}$ & $4.28[70]$ & 5.55 \\
\hline \multirow{2}{*}{$\mathrm{B}_{7}^{-}$} & 4.49 [31] & \multirow{2}{*}{5.07} \\
\hline & $4.48[70]$ & \\
\hline \multirow{3}{*}{$\mathrm{B}_{8}{ }^{0}$} & $4.31[30]$ & \multirow{3}{*}{5.50} \\
\hline & $4.33[31]$ & \\
\hline & $4.41[70]$ & \\
\hline $\mathrm{B}_{8}^{+}$ & $4.42[70]$ & 5.53 \\
\hline \multirow{2}{*}{$\mathrm{B}_{8}^{-}$} & $4.71[31]$ & \multirow{2}{*}{4.88} \\
\hline & $4.71[70]$ & \\
\hline \multirow{2}{*}{$\mathrm{B}_{9}{ }^{0}$} & $4.30[30]$ & \multirow{2}{*}{5.00} \\
\hline & $4.39[70]$ & \\
\hline $\mathrm{B}_{9}^{+}$ & $4.46[70]$ & 5.25 \\
\hline $\mathrm{B}_{0^{-}}^{-}$ & $4.55[31]$ & 425 \\
\hline В9 & $4.71[70]$ & 4.25 \\
\hline & $4.45[30]$ & \\
\hline $\mathrm{B}_{10}{ }^{0}$ & $4.56[70]$ & 5.96 \\
\hline & $5.78[71]$ & \\
\hline $\mathrm{B}_{10}{ }^{+}$ & $4.57[70]$ & 5.84 \\
\hline $\mathrm{B}_{10^{-}}$ & $4.79[70]$ & 5.24 \\
\hline
\end{tabular}


Table 2. Cont.

\begin{tabular}{ccc}
\hline Cluster & Literature Data & Diatomic Model \\
\hline $\mathrm{B}_{11}{ }^{0}$ & $4.52[30]$ & 5.63 \\
\hline $\mathrm{B}_{11}{ }^{+}$ & $4.63[70]$ & 5.45 \\
\hline $\mathrm{B}_{11}{ }^{-}$ & $4.69[70]$ & 6.23 \\
\hline $\mathrm{B}_{12}{ }^{0}$ & $4.89[70]$ & \\
& $4.60[30]$ & 5.77 \\
\hline $\mathrm{B}_{12}{ }^{+}$ & $4.60[67]$ & \\
\hline $\mathrm{B}_{12}{ }^{-}$ & $4.71[70]$ & 6.15 \\
\hline $\mathrm{B}_{13}{ }^{0}$ & $4.72[70]$ & 5.72 \\
\hline $\mathrm{B}_{13}{ }^{+}$ & $4.85[70]$ & 6.26 \\
\hline $\mathrm{B}_{13}{ }^{-}$ & $4.67[70]$ & 6.03 \\
\hline
\end{tabular}

Table 3. Comparison of the literature data on specific fragmentation energies (in eV) of boron small clusters with values calculated in diatomic model.

\begin{tabular}{ccc}
\hline Chanel & Literature Data & Diatomic Model \\
\hline $\mathrm{B}_{3}{ }^{0} \rightarrow \mathrm{B}_{2}{ }^{0}+\mathrm{B}_{1}{ }^{0}$ & $1.24[51]$ & 1.48 \\
\hline $\mathrm{B}_{3}{ }^{+} \rightarrow \mathrm{B}^{0}{ }^{0}+\mathrm{B}_{1}{ }^{+}$ & $0.36[68]$ & 1.29 \\
\hline $\mathrm{B}_{3}{ }^{+} \rightarrow \mathrm{B}_{2}{ }^{+}+\mathrm{B}_{1}{ }^{0}$ & $1.08[82]$ & 0.73 \\
\hline $\mathrm{B}_{4}{ }^{+} \rightarrow \mathrm{B}_{3}{ }^{0}+\mathrm{B}_{1}{ }^{+}$ & $0.50[68]$ & 1.09 \\
\hline $\mathrm{B}_{4}{ }^{+} \rightarrow \mathrm{B}_{3}{ }^{+}+\mathrm{B}_{1}{ }^{0}$ & $0.44[68]$ & 1.84 \\
\hline $\mathrm{B}_{4}{ }^{+} \rightarrow \mathrm{B}_{2}{ }^{0}+\mathrm{B}_{2}{ }^{+}$ & $1.06[82]$ & 2.39 \\
\hline $\mathrm{B}_{5}{ }^{+} \rightarrow \mathrm{B}_{4}{ }^{0}+\mathrm{B}_{1}{ }^{+}$ & $0.70[68]$ & 1.24 \\
\hline $\mathrm{B}_{6}{ }^{+} \rightarrow \mathrm{B}_{5}{ }^{+}+\mathrm{B}_{1}{ }^{0}$ & $0.80[68]$ & 2.02 \\
\hline $\mathrm{B}_{7}{ }^{+} \rightarrow \mathrm{B}_{6}{ }^{+}+\mathrm{B}_{1}{ }^{0}$ & $0.50[68]$ & 1.66 \\
\hline $\mathrm{B}_{8}{ }^{+} \rightarrow \mathrm{B}_{7}{ }^{+}+\mathrm{B}_{1}{ }^{0}$ & $1.24[82]$ & 1.35 \\
\hline $\mathrm{B}_{9}{ }^{+} \rightarrow \mathrm{B}_{8}{ }^{+}+\mathrm{B}_{1}{ }^{0}$ & $0.55[68]$ & 0.75 \\
\hline $\mathrm{B}_{10}{ }^{+} \rightarrow \mathrm{B}_{9}{ }^{+}+\mathrm{B}_{1}{ }^{0}$ & $1.03[82]$ & 1.86 \\
\hline $\mathrm{B}_{11}{ }^{+} \rightarrow \mathrm{B}_{10}{ }^{+}+\mathrm{B}_{1}{ }^{0}$ & $1.01[82]$ & 0.39 \\
\hline $\mathrm{B}_{12}{ }^{+} \rightarrow \mathrm{B}_{11}{ }^{+}+\mathrm{B}_{1}{ }^{0}$ & $1.26[82]$ & 2.31 \\
\hline $\mathrm{B}_{13}{ }^{+} \rightarrow \mathrm{B}_{12}{ }^{+}+\mathrm{B}_{1}{ }^{0}$ & $1.07[82]$ & 1.15 \\
\hline $\mathrm{B}_{14}{ }^{+} \rightarrow \mathrm{B}_{13}{ }^{+}+\mathrm{B}_{1}{ }^{0}$ & $0.99[82]$ & \\
\hline
\end{tabular}

\section{Conclusions}

In summary, a previously developed diatomic-type model for calculating clusters' specific (per atom) binding energy was applied to obtain this key parameter for boron small planar clusters' $\left(\mathrm{B}_{n}, n=2-15\right)$ ground-state isomers in different charge states. The main result of the conducted study was that, in any of the three considered (neutral, singlecationic and single-anionic) charge states, the formation of $\mathrm{B}_{11}-\mathrm{B}_{13}$ clusters is preferable. In 
general features, it is in good agreement with the available experimental data and previous theoretical reports.

As for quantitative agreement in specific binding and fragmentation energies, the diatomic model predicts the values in magnitude comparable with previous results, but it usually overestimates them. These deviations could be explained by different sets of assumptions made in theoretical calculations and/or too significant errors in experimental determination of boron clusters' energy characteristics, one of which ( $B_{2}$ molecule dissociation energy), in particular, serves for key phenomenological parameter in diatomic model approach to calculating cluster specific binding energy.

Specific binding energies and $\mathrm{B}-\mathrm{B}$ bond lengths of most stabile neutral, positively and negatively charged species are $\mathrm{B}_{13}{ }^{0}-6.26 \mathrm{eV}$ and $1.59 \AA, \mathrm{B}_{12}{ }^{+}-6.15 \mathrm{eV}$ and $1.59 \AA$ and $\mathrm{B}_{11}{ }^{-}-6.23 \mathrm{eV}$ and $1.58 \AA$, respectively.

The success of the diatomic approach can serve for the basis for more detailed calculations of boron small clusters, including not only ground-state, but all the possible planar structural isomers, as well as competitive ring-like clusters. In this way, one can determine not only the specific binding energy but also other important characteristics, such as the cluster dipole moment, ionization potential and electron affinity, vibration, atomization, fragmentation energies, etc.

These results would be not only academic, but also practical interests, as boron (quasi)planar clusters serve for building blocks of borophene and other boron-based nanomaterials perspective for variety of technological applications, such as thin super-hard coatings, radiation shielding, solid fuel production, nanoelectronics, etc.

Funding: This research received no external funding.

Institutional Review Board Statement: Not applicable.

Informed Consent Statement: Not applicable.

Data Availability Statement: Data available via personal communication with proper reasons.

Conflicts of Interest: The author declares no conflict of interest.

Sample Availability: Samples of the compounds are not available from the authors.

\section{References}

1. Boustani, I. Towards novel boron nanostructural materials. Chem. Modell. 2011, 8, 1-44.

2. Chkhartishvili, L. Micro- and nano-structured boron. In Boron: Compounds, Production and Application; Perkins, G.L., Ed.; Nova Sci. Publ.: New York, NY, USA, 2011; Chapter 6; pp. 221-294.

3. Chkhartishvili, L. Nanoboron (An overview). Nano Studies 2011, 3, 227-314.

4. Becker, R.; Chkhartishvili, L.; Martin, P. Boron, the new graphene? Vac. Technol. Coat. 2015, 16, $38-44$.

5. Chkhartishvili, L. All-boron nanostructures. In CRC Concise Encyclopedia of Nanotechnology; Kharisov, B.I., Kharissova, O.V., Ortiz-Mendez, U., Eds.; CRC Press: Boca Raton, FL, USA, 2016; Chapter 7; pp. 53-69.

6. $\quad$ Li, D.; Gao, J.; Cheng, P.; He, J.; Yin, Y.; Hu, Y.; Chen, L.; Cheng, Y.; Zhao, J. 2D boron sheets: Structure, growth, and electronic and thermal transport properties. Adv. Funct. Mater. 2019, 30, 1904349. [CrossRef]

7. Tian, Y.; Guo, Z.; Zhang, T.; Lin, H.; Li, Z.; Chen, J.; Deng, S.; Liu, F. Inorganic boron-based nanostructures: Synthesis, optoelectronic properties, and prospective applications. Nanomaterials 2019, 9, 538. [CrossRef] [PubMed]

8. Boustani, I. Molecular Modelling and Synthesis of Nanomaterials. Applications in Carbon-and Boron-Based Nanotechnology; Springer Nature: Cham, Switzerland, 2020.

9. Matsuda, I.; Wu, K. (Eds.) 2D Boron: Boraphene, Borophene, Boronene; Springer Nature: Cham, Switzerland, 2021.

10. Alexandrova, A.N.; Boldyrev, A.I.; Zhai, H.-J.; Wang, L.-S. All-boron aromatic clusters as potential new inorganic ligands and building blocks in chemistry. Coord. Chem. Rev. 2006, 250, 2811-2866. [CrossRef]

11. Li, W.-L.; Chen, Q.; Tian, W.-J.; Bai, H.; Zhao, Y.-F.; Hu, H.-S.; Li, J.; Zhai, H.-J.; Li, S.-D.; Wang, L.-S. The B 35 cluster with a double-hexagonal vacancy: A new and more flexible structural motif for borophene. J. Am. Chem. Soc. 2014, 136, 12257-12260. [CrossRef]

12. Kiran, B.; Bulusu, S.; Zhai, H.-J.; Yoo, S.; Zeng, X.C.; Wang, L.-S. Planar-to-tubular structural transition in boron clusters: $B_{20}$ as the embryo of single-walled boron nanotubes. Proc. Natl. Acad. Sci. USA 2005, 102, 961-964. [CrossRef]

13. Boustani, I. Structural transitions and properties of boron nanoclusters. In 17th International Symposium on Boron, Borides and Related Materials; Istanbul Tech. Univ.: Istanbul, Turkey, 2011; p. 49. 
14. Arvanitidis, A.G.; Tai, T.B.; Nguyen, M.T.; Ceulemans, A. Quantum rules for planar boron nanoclusters. Phys. Chem. Chem. Phys. 2014, 16, 18311-18318. [CrossRef]

15. Verhaegen, G.; Drowart, J. Mass spectrometric determination of the heat of sublimation of boron and the dissociation energy of B . J. Chem. Phys. 1962, 37, 1367-1368. [CrossRef]

16. Mar, R.W.; Bedford, R.G. The sublimation of boron. High. Temp. Sci. 1976, 8, 365-376.

17. Goltz, D.M.; Chakrabarti, C.L.; Sturgeon, R.E.; Hughes, D.M.; Gregoire, D.C. Investigation of the vaporization and atomization of boron in a graphite furnace using digital imaging techniques. Appl. Spectrosc. 1995, 49, 1006-1016. [CrossRef]

18. Becker, R.C. Method for Generating a Boron Vapor. U.S. Patent \# 5861630, 19 January 1999.

19. Boustani, I.; Becker, R. Boron clusters, single- and multiwalled nanotubes: Theoretical prediction and experimental observation. In Proc. 9th Ann. Nanotechnol. Conf. E Trade Show; Nano Sci. \& Technol. Inst.: Boston, MA, USA, 2006; MO 60.802.

20. Medvedovski, E. Preparation of boron nitride-based coatings through thermal diffusion process. Adv. Appl. Ceram. 2018, 117, 221-230. [CrossRef]

21. Unsal, H.; Grasso, S.; Kovalcikova, A.; Hanzel, O.; Tatarkova, M.; Dlouhy, I.; Tatarko, P. In-situ graphene platelets formation and its suppression during reactive spark plasma sintering of boron carbide/titanium diboride composites. J. Eur. Ceram. Soc. 2021, 41, 6281-6289. [CrossRef]

22. Feldman, C.; Moorjani, K.; Blum, N.A. Mass-spectrometry, optical absorption, and electrical properties of boron amorphous films. In Boron-Obtaining, Structure, and Properties; Tsagareishvili, G.V., Tavadze, F.N., Eds.; Nauka: Moscow, Russia, 1974; pp. 130-138. (In Russian)

23. Kutelia, E.R.; Dekanosidze, R.N.; Maisuradze, N.I.; Dzigrashvili, T.A.; Petrov, V.I. Electron microscopic investigation of the structure of ultrafine elementary boron. In Abs. 8th Int. Symp. Boron, Borides, Carbides, Nitrides E Rel. Comp.; Tsagareishvili, G.V., Ed.; Metsniereba: Tbilisi, Georgia, 1984; pp. 12-13.

24. Kervalishvili, P.J.; Kutelia, E.R.; Dzigrashvili, T.A.; Dekanosidze, R.N.; Petrov, V.I. Electron-microscopic study of amorphous boron structure. Phys. Solid State 1985, 27, 1414-1418. (In Russian)

25. Dzigrashvili, T.A.; Kutelia, E.R. On structural relaxation of small particles. Bull. Acad. Sci. Georgian SSR 1988, 129, 53-56. (In Russian)

26. La Placa, S.J.; Roland, P.A.; Wynne, J.J. Boron clusters $\left(\mathrm{B}_{n}, n=2-52\right)$ produced by laser ablation of hexagonal boron nitride. Chem. Phys. Lett. 1992, 190, 163-168. [CrossRef]

27. Liu, C.H.; Peng, W.; Sheng, L.M. Carbon and boron nanoparticles by pulsed-laser vaporization of boron carbide in liquids. Carbon 2001, 39, 144-147. [CrossRef]

28. Xu, S.-J.; Nilles, J.M.; Radisic, D.; Zheng, W.-J.; Stokes, S.; Bowen, K.H.; Becker, R.C.; Boustani, I. Boron cluster anions containing multiple $\mathrm{B}_{12}$ icosahedra. Chem. Phys. Lett. 2003, 379, 282-286. [CrossRef]

29. Oger, E. Strukturaufklärung durch Mobilitätsmessungen an Massenselektierten Clusterionen in der Gasphase (Dissertation); KIT Sci. Publ.: Karlsruher, Germany, 2010. (In German)

30. Atis, M.; Ozdogan, C.; Guvenc, Z.B. Structure and energetic of $\mathrm{B}_{n}(n=2-12)$ clusters: Electronic structure calculations. Int. J. Quantum Chem. 2007, 107, 729-744. [CrossRef]

31. Tai, T.B.; Grant, D.J.; Nguyen, M.T.; Dixon, D.A. Thermochemistry and electronic structure of small boron clusters $\left(\mathrm{B}_{n}, n=5-13\right)$ and their anions. J. Phys. Chem. A 2010, 114, 994-1007. [CrossRef] [PubMed]

32. Tai, T.B.; Nguyen, M.T. Electronic structure and photoelectron spectra of $\mathrm{B}_{n}$ with $n=26-29$ : An overview of structural characteristics and growth mechanism of boron clusters. Phys. Chem. Chem. Phys. 2015, 17, 13672-13679. [CrossRef] [PubMed]

33. Wu, X.; Sai, L.; Zhou, S.; Zhou, P.; Chen, M.; Springborg, M.; Zhao, J. Competition between tubular, planar and cage geometries: A complete picture of structural evolution of $\mathrm{B}_{n}(n=31-50)$ clusters. Phys. Chem. Chem. Phys. 2020, 22, 12959-12966. [CrossRef] [PubMed]

34. Vedeneev, V.I.; Gurvich, L.V.; Kondrat'ev, V.N.; Medvedev, V.L.; Frankevich, E.L. Chemical Bonds Breaking Energy. Ionization Potentials and Electron Affinity (Handbook); Acad. Sci. USSR: Moscow, Russia, 1962. (In Russian)

35. Graham, W.R.M.; Weltner, W. B atoms, $\mathrm{B}_{2}$ and $\mathrm{H}_{2} \mathrm{BO}$ molecules: ESR and optical spectra at 4 K. J. Chem. Phys. 1976, 65, 1516-1521. [CrossRef]

36. Dupuis, M.; Liu, B. The ground electronic state of B2. J. Chem. Phys. 1978, 68, 2902-2910. [CrossRef]

37. Martin, J.M.L.; Francois, J.P.; Gijbels, R. Ab initio study of boron, nitrogen, and boron-nitrogen clusters. I. Isomers and thermochemistry of $\mathrm{B}_{3}, \mathrm{~B}_{2} \mathrm{~N}, \mathrm{BN}_{2}$, and $\mathrm{N}_{3}$. J. Chem. Phys. 1989, 90, 6469-6485. [CrossRef]

38. Deutsch, P.W.; Curtiss, L.A.; Pople, J.A. Boron dimer: Dissociation energy and ionization potentials. Chem. Phys. Lett. 1990, 174, 33-36. [CrossRef]

39. Huber, K.P.; Herzberg, H. Molecular Spectra and Molecular Structure. IV. Constants of Diatomic Molecules; van Nostrand Reinhold Co.: New York, NY, USA, 1979.

40. Langhoff, S.R.; Bauschlicher, C.W. Theoretical study of the spectroscopy of B2. J. Chem. Phys. 1991, 95, 5882-5888. [CrossRef]

41. Chkhartishvili, L.; Lezhava, D.; Tsagareishvili, O.; Gulua, D. Ground-state parameters of diatomic molecules B2, BC, BN, and BO Proc. Georgian Police Acad. 1999, 1, 195-300. (In Russian)

42. Chkhartishvili, L.; Lezhava, D.; Tsagareishvili, O. Quasi-classical determination of electronic energies and vibration frequencies in boron compounds. J. Solid State Chem. 2000, 154, 148-152. [CrossRef] 
43. Chkhartishvili, L. On quasi-classical estimations of boron nanotubes ground-state parameters. J. Phys. Conf. Ser. 2009, 176, 012013. [CrossRef]

44. Chkhartishvili, L. Molar binding energy of the boron nanosystems. In Proceedings of the 4th International Boron Symposium; Konuk, A., Kurama, H., Ak, H., Iphar, M., Eds.; Osmangazi Univ.-TMMOB: Ankara, Turkey, 2009; pp. 153-160.

45. Chkhartishvili, L. Nanotubular boron: Ground-state estimates. In New Developments in Materials Science; Chikoidze, E., Tchelidze, T., Eds.; Nova Sci. Publ.: New York, NY, USA, 2013; Chapter 8; pp. 67-80.

46. Bruna, P.J.; Wright, J.S. Strongly bound multiply excited states of $\mathrm{B}_{2}{ }^{+}$and $\mathrm{B}_{2}$. J. Chem. Phys. 1989, 91, 1126-1136. [CrossRef]

47. Mierzwa, G.; Gordon, A.J.; Berski, S. The nature of the triple B $\equiv$ B, double B=B, single B-B, and one-electron B-B boron-boron bonds from the topological analysis of Electron Localization Function (ELF) perspective. J. Mol. Str. 2020, 1221, 128530. [CrossRef]

48. Boustani, I. New convex and spherical structures of bare boron clusters. J. Solid State Chem. 1997, 133, 182-189. [CrossRef]

49. Boustani, I. New quasi-planar surfaces of bare boron. Surf. Sci. 1997, 370, 355-363. [CrossRef]

50. Boustani, I.; Quandt, A. Boron in ab initio calculations. Comput. Mater. Sci. 1998, 11, 132-137. [CrossRef]

51. Hernandez, R.; Simons, J. Electronic energies, geometries, and vibrational frequencies of the ground and low-lying excited states of the boron trimer. J. Chem. Phys. 1991, 94, 2961-2967. [CrossRef]

52. Zhai, H.-J.; Wang, L.-S.; Alexandrova, A.N.; Boldyrev, A.I.; Zakrzewski, V.G. Photoelectron spectroscopy and ab initio study of $\mathrm{B}_{3}{ }^{-}$and $\mathrm{B}_{4}{ }^{-}$anions and their neutrals. J. Chem. Phys. A 2003, 107, 9319-9328. [CrossRef]

53. Martin, J.M.L.; Francois, J.P.; Gijbels, R. Potential energy surface of $\mathrm{B}_{4}$ and total atomization energies of $\mathrm{B}_{2}, \mathrm{~B}_{3}$, and $\mathrm{B}_{4}$. Chem. Phys. Lett. 1992, 189, 529-536. [CrossRef]

54. Koutecky, J.; Pacchioni, G.; Jeung, G.H.; Hass, E.C. Comparative study of tetramers built from Ia, IIa, IIIa, and IVa atoms. Surf. Sci. 1985, 156, 650-669. [CrossRef]

55. Li, Q.S.; Jin, H.W. Structure and stability of $\mathrm{B}_{5}, \mathrm{~B}_{5}{ }^{+}$, and $\mathrm{B}_{5}{ }^{-}$clusters. J. Phys. Chem. A 2002, 106, 7042-7047. [CrossRef]

56. Zhai, H.-J.; Wang, L.-S.; Alexandrova, A.N.; Boldyrev, A.I. Electronic structure and chemical bonding of $\mathrm{B}_{5}{ }^{-}$and $\mathrm{B}_{5}$ by photoelectron spectroscopy and ab initio calculations. J. Chem. Phys. 2002, 117, 7917-7924. [CrossRef]

57. Alexandrova, A.N.; Boldyrev, A.I.; Zhai, H.-J.; Wang, L.-S.; Steiner, E.; Fowler, P.W. Structure and bonding in $\mathrm{B}_{6}{ }^{-}$and $\mathrm{B}_{6}$ : Planarity and antiaromaticity. J. Phys. Chem. A 2003, 107, 1359-1369. [CrossRef]

58. Alexandrova, A.N.; Boldyrev, A.I.; Zhai, H.-J.; Wang, L.-S. Electronic structure, isomerism, and chemical bonding in $\mathrm{B}_{7}^{-}$and $\mathrm{B}_{7} . \mathrm{J}^{-}$ Phys. Chem. A 2004, 108, 3509-3517. [CrossRef]

59. Hanley, L.; Anderson, S.L. Production and collision-induced dissociation of small boron cluster ions. J. Phys. Chem. 1987, 91, 5161-5163. [CrossRef]

60. Ray, A.K.; Howard, I.A.; Kanal, K.M. Structure and binding in small neutral and cationic boron clusters. Phys. Rev. B 1992, 45, 14247-14255. [CrossRef]

61. Kato, H.; Tanaka, E. Stabilities of small $\mathrm{Be}_{n}$ and $\mathrm{B}_{n}$ clusters $(4 \leq n \leq 8)$ by vibrational analysis. J. Comput. Chem. 1991, 12, 1097-1109. [CrossRef]

62. Zhai, H.-J.; Alexandrova, A.N.; Birch, K.A.; Boldyrev, A.I.; Wang, L.-S. Hepta- and octacoordinate boron in molecular wheels of eight- and nine-atom boron clusters: Observation and confirmation. Angew. Chem. Int. Ed. 2003, 42, 6004-6008. [CrossRef]

63. Drummond, M.L.; Meunier, V.; Sumpter, B.G. Structure and stability of small boron and boron oxide clusters. J. Phys. Chem. A 2007, 111, 6539-6551. [CrossRef]

64. Kato, H.; Yamashita, K.; Morokuma, K. Ab initio MO study of neutral and cationic boron clusters. Chem. Phys. Lett. 1992, 190, 361-366. [CrossRef]

65. Bambakidis, G.; Wagner, R.P. Electronic structure and binding energy of the icosahedral boron cluster B 12 . J. Phys. Chem. Solids 1981, 42, 1023-1025. [CrossRef]

66. Kawai, R.; Weare, J.H. Instability of the $\mathrm{B}_{12}$ icosahedral cluster: Rearrangement to a lower energy structure. J. Chem. Phys. 1991, 95, 1151-1159. [CrossRef]

67. Bhattacharyya, P.; Boustani, I.; Shukla, A. First principles study of structural and optical properties of $\mathrm{B}_{12}$ isomers. arXiv 2018, arXiv:1802.01072. [CrossRef]

68. Hanley, L.; Whitten, J.L.; Anderson, S.L. Collision-induced dissociation and ab initio studies of boron cluster ions: Determination of structures and stabilities. J. Phys. Chem. 1988, 92, 5803-5812. [CrossRef]

69. Hanley, L.; Whitten, J.L.; Anderson, S.L. Collision-induced dissociation and ab initio studies of boron cluster ions: Determination of structures and stabilities [Erratum to document cited in CA109(18):156723t]. J. Phys. Chem. 1990, 94, 2218. [CrossRef]

70. Akman, N.; Tas, M.; Ozdogan, C.; Boustani, I. Ionization energies, Coulomb explosion, fragmentation, geometric, and electronic structures of multicharged boron clusters $\mathrm{B}_{n}(n=2-13)$. Phys. Rev. B 2011, 84, 075463. [CrossRef]

71. Cao, P.-1.; Zhao, W.; Li, B.-X.; Song, B.; Zhou, X.-Y. A full-potential linear-muffin-tin-orbital molecular-dynamics study of $\mathrm{B}_{7}, \mathrm{~B}_{10}$ and $\mathrm{B}_{13}$ clusters. J. Phys. Cond. Matter 2001, 13, 5065-5076. [CrossRef]

72. Kato, H.; Yamashita, K.; Morokuma, K. Ab initio study of neutral and cationic $\mathrm{B}_{12}$ and $\mathrm{B}_{13}$ clusters. Bull. Chem. Soc. Jpn. 1993, 66, 3358-3361. [CrossRef]

73. Gu, F.L.; Yang, X.; Tang, A.-C.; Jiao, H.; von Schleyer, P.R. Structure and stability of $\mathrm{B}_{13}{ }^{+}$clusters. J. Comput. Chem. 1998, 19, 203-214. [CrossRef]

74. Kiran, B.; Kumar, G.G.; Nguyen, M.T.; Kandalam, A.K.; Jena, P. Origin of the unusual stability of $\mathrm{B}_{12}$ and $\mathrm{B}_{13}{ }^{+}$clusters. Inorg. Chem. 2009, 48, 9965-9967. [CrossRef] 
75. Kawai, R.; Weare, J.H. Anomalous stability of $\mathrm{B}_{13}{ }^{+}$clusters. Chem. Phys. Lett. 1992, 191, 311-314. [CrossRef]

76. Fowler, J.E.; Ugalde, J.M. The curiously stable $\mathrm{B}_{13}{ }^{+}$cluster and its neutral and anionic counterparts: The advantages of planarity. J. Phys. Chem. A 2000, 104, 397-403. [CrossRef]

77. Aihara, J.-I. $\mathrm{B}_{13}{ }^{+}$is highly aromatic. J. Phys. Chem. A 2001, 105, 5486-5489. [CrossRef]

78. Shinde, R.; Tayade, M. Optical absorption in $\mathrm{B}_{13}$ cluster: A Time-dependent density functional approach. AIP Conf. Proc. 2012, G-163, 1-2.

79. Boustani, I. Systematic LSD investigation on cationic boron clusters: $\mathrm{B}_{n}{ }^{+}(n=2-14)$. Int. J. Quant. Chem. 1994, 52, 1081-1111. [CrossRef]

80. Boustani, I. A comparative study of ab initio SCF-CI and DFT. Example of small boron clusters. Chem. Phys. Lett. 1995, 233, 273-278. [CrossRef]

81. Boustani, I. Structure and stability of small boron clusters. A density functional theoretical study. Chem. Phys. Lett. 1995, 240, 135-140. [CrossRef]

82. Ricca, A.; Bauschlicher, C.W., Jr. The structure and stability of $\mathrm{B}_{n}{ }^{+}$clusters. Chem. Phys. 1996, 208, 233-242. [CrossRef]

83. Boustani, I. Systematic ab initio investigation of bare boron clusters: Determination of the geometry and electronic structures of $\mathrm{B}_{n}(n=2-14)$. Phys. Rev. B 1997, 55, 16426-16438. [CrossRef]

84. Zhai, H.-J.; Kiran, B.; Li, J.; Wang, L.-S. Hydrocarbon analogues of boron clusters-Planarity, aromaticity and antiaromaticity. Nat. Mater. 2003, 2, 827-833. [CrossRef]

85. Sergeeva, A.P.; Zubarev, D.Y.; Zhai, H.-J.; Boldyrev, A.I.; Wang, L.-S. A photoelectron spectroscopic and theoretical study of B 16 and $\mathrm{B}_{16}{ }^{2-}$ : An all-boron naphthalene. J. Am. Chem. Soc. 2008, 130, 7244-7246. [CrossRef] [PubMed]

86. Huang, W.; Sergeeva, A.P.; Zhai, H.-J.; Averkiev, B.B.; Wang, L.-S.; Boldyrev, A.I. A concentric planar doubly $\pi$-aromatic B 19 cluster. Nat. Chem. 2010, 2, 202-206. [CrossRef] [PubMed]

87. An, W.; Bulusu, S.; Gao, Y.; Zeng, X.C. Relative stability of planar versus double-ring tubular isomers of neutral and anionic boron cluster $\mathrm{B}_{20}$ and $\mathrm{B}_{20}{ }^{-}$. J. Chem. Phys. 2006, 124, 154310. [CrossRef] [PubMed]

88. Oger, E.; Crawford, N.R.M.; Kelting, R.; Weis, P.; Kappes, M.M.; Ahlrichs, R. Boron cluster cations: Transition from planar to cylindrical structures. Angew. Chem. Int. Ed. 2007, 46, 8503-8506. [CrossRef]

89. Chacko, S.; Kanhere, D.G.; Boustani, I. Ab initio density functional investigation of $\mathrm{B}_{24}$ clusters: Rings, tubes, planes, and cages. Phys. Rev. B 2003, 68, 035414. [CrossRef]

90. Piazza, Z.A.; Popov, I.A.; Li, W.-L.; Pal, R.; Zeng, X.C.; Boldyrev, A.I.; Wang, L.-S. A photoelectron spectroscopy and ab initio study of the structures and chemical bonding of the $\mathrm{B}_{25}{ }^{-}$cluster. J. Chem. Phys. 2014, 141, 034303. [CrossRef]

91. Li, W.-L.; Pal, R.; Piazza, Z.A.; Zeng, X.C.; Wang, L.-S. $\mathrm{B}_{27}{ }^{-}$: Appearance of the smallest planar boron cluster containing a hexagonal vacancy. J. Chem. Phys. 2015, 142, 204305. [CrossRef]

92. Boustani, I.; Rubio, A.; Alonso, J.A. Ab initio study of $\mathrm{B}_{32}$ clusters: Competition between spherical, quasiplanar and tubular isomers. Chem. Phys. Lett. 1999, 311, 21-28. [CrossRef]

93. Chen, Q.; Wei, G.-F.; Tian, W.-J.; Bai, H.; Liu, Z.-P.; Zhai, H.-J.; Li, S.-D. Quasi-planar aromatic B 36 and B $36{ }^{-}$clusters: All-boron analogues of coronene. Phys. Chem. Chem. Phys. 2014, 16, 18282-18287. [CrossRef]

94. Piazza, Z.A.; Hu, H.-S.; Li, W.-L.; Zhao, Y.-F.; Li, J.; Wang, L.-S. Planar hexagonal $\mathrm{B}_{36}$ as a potential basis for extended single-atom layer boron sheets. Nat. Commun. 2014, 5, 3113. [CrossRef]

95. Bai, H.; Chen, T.-T.; Chen, Q.; Zhao, X.-Y.; Zhang, Y.-Y.; Chen, W.-J.; Li, W.-L.; Cheung, L.F.; Bai, B.; Cavanagh, J.; et al. Planar B $41{ }^{-}$ and $\mathrm{B}_{42}{ }^{-}$clusters with double-hexagonal vacancies. Nanoscale 2019, 11, 23286-23295. [CrossRef] [PubMed]

96. Mukhopadhyay, S.; He, H.; Pandey, R.; Yap, Y.K.; Boustani, I. Novel spherical boron clusters and structural transition from 2D quasi-planar structures to 3D double-rings. J. Phys. Conf. Ser. 2009, 176, 012028. [CrossRef]

97. Oyaidzu, M.; Yoshikawa, A.; Kodama, H.; Oya, Y.; Sagara, A.; Noda, N.; Okuno, K. Preparation of pure boron coating film and its characterization by XPS and TDS. Appl. Surf. Sci. 2005, 244, 240-243. [CrossRef]

98. Becker, R.C.; Bunker, S.N. Method for depositing boron-rich coatings. Patent Appl. \# US 2005/0208218 A1, 22 September 2005.

99. Becker, R.; Chkhartishvili, L.; Martin, P. Tribological applications for boron. Vac. Technol. Coat. 2015, 16, 36-41.

100. Korbut, E.V.; Labunets, V.F.; Radko, O.V.; Zagrebelnyi, V.V.; Yakobchuk, O.E. Improve of the high-speed steel wear resistance using boron coating. In Proc. 5th Int. Conf. High Mat Tech; IPMS: Kyiv, Ukraine, 2015; p. 189.

101. Zhu, Z.; Kwon, D.-G.; Kwon, Y.-K.; Tomanek, D. Enhancing mechanical toughness of aluminum surfaces by nano-boron implantation: An ab initio study. Chem. Phys. Lett. 2015, 620, 25-28. [CrossRef]

102. Demirbas, A. Energy from boron and non-nuclear metallic fuels. Energy Sources A 2008, 30, 1108-1113. [CrossRef]

103. Young, G.; Sullivan, K.; Zachariah, M.R.; Yu, K. Combustion characteristics of boron nanoparticles. Combust. Flame 2009, 156, 322-333. [CrossRef]

104. Hussmann, B.; Pfitzner, M. Extended combustion model for single boron particles-Part I: Theory. Combust. Flame 2010, 157, 803-821. [CrossRef]

105. Hussmann, B.; Pfitzner, M. Extended combustion model for single boron particles-Part II: Validation. Combust. Flame 2010, 157, 822-833. [CrossRef]

106. Katoshevski, D.; Chkhartishvili, L. Manipulating grouping dynamics of nanoscale boron particles as basis for environmentally friendlier combustion and efficient filtration. In Nanotechnology in Environmental Science; Hussain, C.M., Mishra, A.K., Eds.; Wiley-VCH Verlag GmbH \& Co. KGaA: Weinheim, Germany, 2018; Chapter 13; pp. 413-442. 
107. Ojha, P.K.; Karmakar, S. Boron for liquid fuel engines-A review on synthesis, dispersion stability in liquid fuel, and combustion aspects. Prog. Aerospace Sci. 2018, 100, 18-45. [CrossRef]

108. Gan, Y.; Lim, Y.S.; Qiao, L. Combustion of nanofluid fuels with the addition of boron and iron particles at dilute and dense concentrations. Combust. Flame 2012, 159, 1732-1740. [CrossRef]

109. Chintersingh, K.-L.; Schoenitz, M.; Dreizin, E.L. Combustion of boron and boron-iron composite particles in different oxidizers. Combust. Flame 2018, 192, 44-58. [CrossRef]

110. Epshteyn, A.; Weismiller, M.R.; Huba, Z.J.; Maling, E.L.; Chaimowitz, A.S. Optimization of a high-energy Ti-Al-B nanopowder fuel. Energy Fuels 2017, 31, 1811-1819. [CrossRef]

111. Hanley, L.; Anderson, S.L. Oxidation of small boron cluster ions $\left(\mathrm{B}_{1-13}{ }^{+}\right)$by oxygen. J. Chem. Phys. 1988, 89, 2848-2860. [CrossRef]

112. Ruatta, S.A.; Hintz, P.A.; Anderson, S.L. Boron cluster ion oxidation: Reactions with $\mathrm{CO}_{2}$, dissociation of boron cluster oxide $\left(\mathrm{B}_{n} \mathrm{O}^{+}\right)$ions, and sequential oxidation. J. Chem. Phys. 1991, 94, 2833-2847. [CrossRef]

113. Chkhartishvili, L.; Tsagareishvili, O.; Gabunia, D. ${ }^{10}$ B-based materials for neutron-shielding. In Proc. 1st Int. Conf. "Modern Technologies and Methods of Inorganic Materials Science"; Khantadze, J., Chkhartishvili, L., Gabunia, D., Ramazashvili, D., Eds.; Meridian: Tbilisi, Georgia, 2012; pp. 188-202.

114. Chkhartishvili, L. Interaction between neutron-radiation and boron-containing materials. In Radiation Synthesis of Materials and Compounds; Kharisov, B.I., Kharissova, O.V., Mendez, U.O., Eds.; CRC Press-Taylor \& Francis Group: Boca Raton, FL, USA, 2013; Chapter 3; pp. 43-80.

115. Chkhartishvili, L. Boron-contained nanostructured materials for neutron-shields. In Nanostructured Materials for the Detection of CBRN; Bonca, J., Kruchinin, S., Eds.; Springer Science: Dordrecht, The Netherlands, 2018; Chapter 11; pp. 133-154.

116. Chkhartishvili, L. Neutron-fluence nanosensors based on boron-containing materials. In Nanomaterials for Environmental Protection; Kharisov, B.I., Kharissova, O.V., Rasika Dias, H.V., Eds.; John Wiley \& Sons Inc.: Hoboken, NJ, USA, 2014; Chapter 26; pp. 445-449.

117. Chkhartishvili, L.; Tsagareishvili, O.; Tavadze, G. Neutron detectors based on ${ }^{10} \mathrm{~B}$-containing nanomaterials. In Nuclear Radiation Nanosensors and Nanosensory Systems; Kervalishvili, P.J., Yannakopoulos, P.H., Eds.; Springer Science: Dordrecht, The Netherlands, 2016; Chapter 12; pp. 187-196.

118. Chkhartishvili, L.; Murusidze, I. Band structure of all-boron 2D metallic crystals as a prospective electromagnetic shielding material. In Proc. Int. Conf. "Fundamental and Applied Nano Electromagnetics"; Belarusian State Univ.: Minsk, Belarus, $2012 ;$ p. 11.

119. Wang, Y.-J.; Zhao, X.-Y.; Chen, Q.; Zhai, H.-J.; Li, S.-D. B ${ }_{11}^{-}$: A moving subnanoscale tank tread. Nanoscale 2015, 7, 16054-16060. [CrossRef]

120. He, C.-C.; Xu, S.-G.; Zhao, Y.-J.; Xu, H.; Yang, X.-B. All-boron planar ferromagnetic structures: From clusters to monolayers. Nanoscale 2021, 13, 9881-9887. [CrossRef]

121. Wang, Z.-Q.; Lu, T.-Y.; Wang, H.-Q.; Feng, Y.P.; Zheng, J.-C. Review of borophene and its potential applications. Front. Phys. 2019, 14, 33403. [CrossRef]

122. Fermi, E. Molecules and Crystals; Barth: Leipzig, Germany, 1938.

123. Novikova, S.I. Thermal Expansion of Solids; Nauka: Moscow, Russia, 1974. (In Russian)

124. Slutsker, A.I.; Gilyarov, V.L.; Luk'yanenko, A.S. Energy features of an adiabatically loaded anharmonic oscillator. Phys. Solid State 2006, 48, 1947-1953. [CrossRef]

125. Chkhartishvili, L.; Becker, R.; Avci, R. Relative stability of boron quasi-planar clusters. In Proc. Int. Conf. "Advanced Materials and Technologies"; Darsavelidze, G., Guldamashvili, A., Chedia, R., Sichinava, A., Kadaria, M., Eds.; Universal: Tbilisi, Georgia, 2015; pp. 42-46.

126. Chkhartishvili, L. Small elemental clusters in pair interaction approximation. In Proc. 4th Int. Conf. Exh. Adv. Nano Mater.; IAEMM: Montreal, QC, Canada, 2016; pp. 128-132.

127. Chkhartishvili, L. Quasi-planar elemental clusters in pair interactions approximation. Open Phys. 2016, 14, 617-620. [CrossRef]

128. Chkhartishvili, L. Planar clusters of identical atoms in equilibrium: 1. Diatomic model approach. Am. J. Nano Res. Appl. 2017, 5, $1-4$.

129. Chkhartishvili, L.; Becker, R. Effective atomic charges and dipole moment of small boron clusters. In Proc. 3rd Int. Conf. Exh. Adv. Nano Mater.; IAEMM: Ottawa, ON, Canada, 2015; pp. 130-147.

130. Becker, R.; Chkhartishvili, L. Dipole moment of quasi-planar boron clusters. Nano Studies 2015, 11, $29-48$.

131. Chkhartishvili, L. Boron quasi-planar clusters. A mini-review on diatomic approach. In Proc. IEEE 7th Int. Conf. Nanomaterials: Applications \& Properties (NAP-2017), Track: Nanomaterials for Electronics, Spintronics and Photonics; Sumy State Univ.: Sumy, Ukraine, 2017; Part 4; pp. 04NESP10-1-04NESP10-5.

132. Chkhartishvili, L. Boron triangular sheet: Calculation of ground-state and electronic-structure parameters. In Proc. 7th Int. Conf. Exh. Adv. Nano Mater.; IAEMM: Montreal, QC, Canada, 2019; pp. 11-16.

133. Chkhartishvili, L. Relative stability of planar clusters $\mathrm{B}_{11}, \mathrm{~B}_{12}$, and $\mathrm{B}_{13}$ in neutral- and charged-states. Char. Appl. Nanomater. 2019, 2, 761-1-761-7. [CrossRef]

134. Chkhartishvili, L.; Murusidze, I.; Becker, R. Electronic structure of boron flat holeless sheet. Condensed Matter 2019, 4, 28. [CrossRef]

135. Chkhartishvili, L. Nanoclusters binding energy in diatomic model. Int. J. Adv. Nano Comput. Anal. 2021, 1, 80-83. 